Portland State University

PDXScholar

\title{
Adolescent chemical substance use and abuse : environmental and personal determinants, and a proposed model for group intervention
}

Lindy Louise Low LeCoq

Portland State University

Follow this and additional works at: https://pdxscholar.library.pdx.edu/open_access_etds

Part of the Counseling Commons, Education Commons, and the Substance Abuse and Addiction Commons

Let us know how access to this document benefits you.

\section{Recommended Citation}

LeCoq, Lindy Louise Low, "Adolescent chemical substance use and abuse : environmental and personal determinants, and a proposed model for group intervention" (1982). Dissertations and Theses. Paper 3193.

https://doi.org/10.15760/etd.3184

This Thesis is brought to you for free and open access. It has been accepted for inclusion in Dissertations and Theses by an authorized administrator of PDXScholar. Please contact us if we can make this document more accessible: pdxscholar@pdx.edu. 
AN ABSTRACT OF THE THESIS OF Lindy Louise Low LeCog for the Master of Science in Education presented May 6, 1982.

Title: Adolescent Chemical Substance Use and Abuse: Environmental and Personal Deterninants and a Proposed Model for Group Intervention. APPROVED BY MEMBERS OF THE THESIS COMMITTEE:

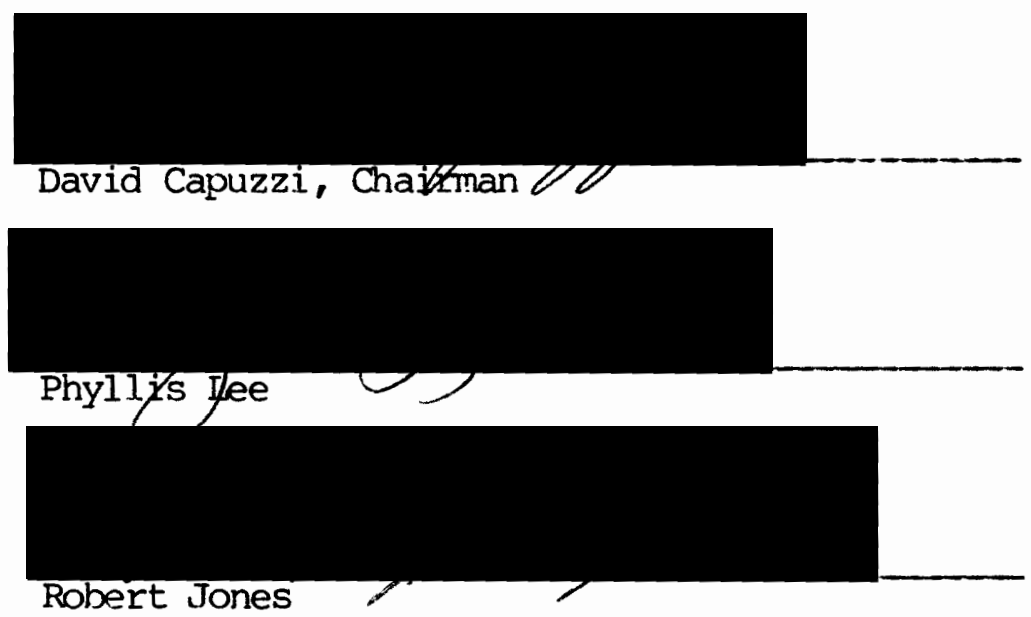

The purpose of the literature review is to identify consistent patterns regarding adolescent use and abuse of chemical substances, especially alcohol and marijuana. Acute physical, cognitive and social effects of alcohol and marijuana use are outlined, and environmental and personal determinants of drug use and abuse are examined. Methods of prevention and intervention are discussed and, from the research findings, a model group counseling program designed for the school setting is proposed. Adolescent use of both marijuana and alcohol is found to be modal by age 16-17. The physical, cognitive and social effects are pervasive and especially damaging to chronic users. Youth 
are extremely vulnerable to suffering adversity from their drug use patterns.

Environmental elements which appear to predict adolescent chemical substance use and abuse include: a) presence of role models who use/ abuse drugs; b) lack of close family affinity; c) greater peer relative to parent saliency; and, d) association with drug using peers.

Those personal factors which are likely to predict adolescent chemical substance use and abuse include holding a positive attitude toward drug use and expecting a favorable outcome from use of a drug, usually an increase in pleasure or a decrease in disconfort. High need for internal sensation stimulation, high impulsiveness, risk taking and rebelliousness, high value on independence relative to low value on achievement, and low self-esteem are all closely correlated to adolescent chemical substance use and abuse. Coping skills, interpersonal relationship skills, and gender role socialization also influence the adolescent's decision to use or abuse drugs.

Drug education programs employing scare tactics and misinformation create reactivism in adolescents. Prevention and intervention based on classroom information dispensing also are of questionable efficiacy. Therefore it is suggested that drug intervention programs integrate decision making, coping skills and values with accurate information to help adolescents make positive personal choices. The model group program of 10 ninety minute sesions is designed to assist adolescents, who are making decisions regarding their own use or abuse of chemical substances; a) identify elements active in their current internal and external environment which precipitates drug use, b) learn and practice new coping methods, and c) examine drug use and abuse relative to their 
current and future values and lifestyle preferences.

The model group program is suggested as part of an ongoing commitment by the school guidance department as part of an overall plan which the school district could develop. Involving other resources of the cormunity in drug use and abuse prevention, intervention and rehabilitation is recommended. 
ADOLESCENT OHEMICAL SUBSTANCE USE AND ABUSE:

ENVIRONMENTIAL AND PERSONAL DETERMINANTS, AND A PROPOSED MODEL FOR GROUP INTERVENTION

by

LINDY LOUISE LOW LECOQ

A thesis submitted in partial fulfillment of the requirements for the degree of

MASTER OF SCIENCE

in

EDUCATION

Portland State University 
TO THE OFFICE OF GRADUATE STUDIES AND RESEARCH:

The members of the Committee approve the thesis of Lindy Louise Low LeCoq presented Mlay 6, 1982.

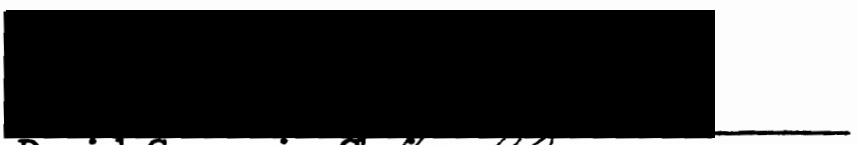

David Capuzzi, Chairmant

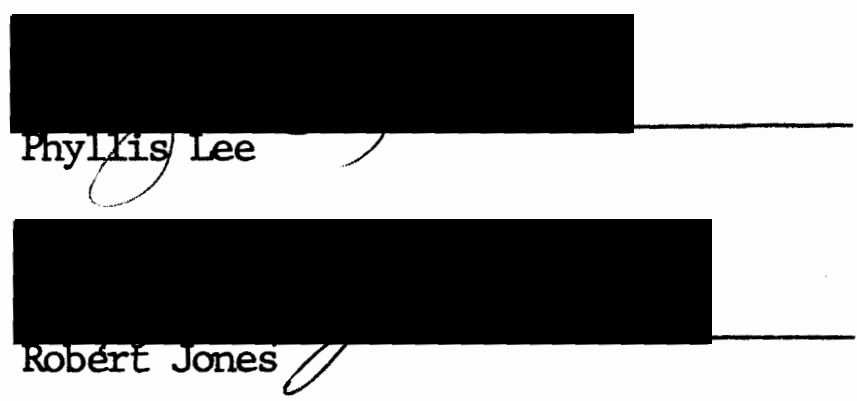

APPROVED:

Carol A. Burden, Head, Department of Special Programs

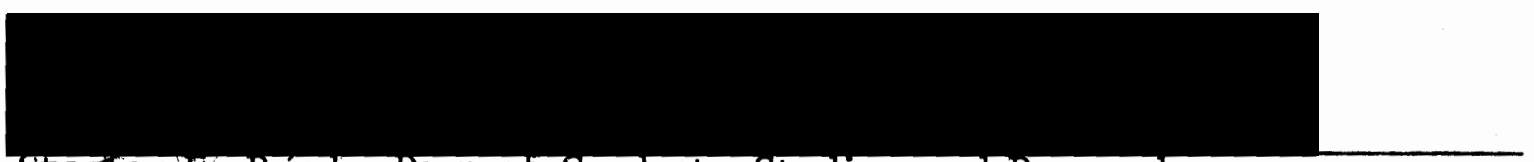

Stanley 1. Rauch, Dean of Graduate Studies and Research 


\section{ACKNOWLEDGEMENTS}

This thesis would not have been possible without the encouragement, sacrifice, and assistance of a few very special people. First, I wish to express my sincere gratitude to $\mathrm{Dr}$. Dave Capuzzi, chairperson of my master's conmittee, for his positive approach and energy, the many hours he spent in my behalf, and for maintaining a lively humour during times of stress. Much appreciation also goes to committee members Phyllis Lee for the manuscript improvements she suggested, and to Dr. Robert Jones for introducing me to social learning theory.

Also, I wish to thank my husband, Creighton, for his conscientious encouragement and support of my goals. His patience, flexibility, and faith in me, have inspired me to persevere through the difficult times. I believe his sacrifices will be returned in kind.

Finally, I wish to thank my family for years of love and warmth, my parents for maintaining democratic principles within our home, my father for instilling me with a positive belief in my abilities, and my mother for her strength and courage. 
TABLE OF CONTENTS

PAGE

ACKNOWLEDGEMENTS . . . . . . . . . . . . . iii

LIST OF TABLES . . . . . . . . . . . . . . vii

CHAPTER

I INTRODUCTION .................... 1

II EXTENT OF THE PROBLEM AND ACUTE EFFECTS . . . . . . 5

Extent of Alcohol Use ........... 5

Extent of Marijuana Use ........... 6

Extent of Multiple Drug Use . . . . . . . . 8

Acute Effects of Alcohol .......... 10

Acute Effects of Marijuana ......... . 13

III MOTIVATION FOR CHEMICAL SUBSTANCE USE: ENVIRONMENTAL

DETERMINANTS . . . . . . . . . . . . . . 18

Reinforcement and Modeling ........ . . 18

Historical Perspective and Social Influence . . . 19

Religious Affiliation . . . . . . . . 21

Parental Influence . . . . . . . . . . 22

Peer Influence . . . . . . . . . . . 25

School Influence ... . . . . . . . . 28

Sumnary . . . . . . . . . . . . 30

IV MOTIVATION FOR CHEMICAL SUJBSTANCE USE:

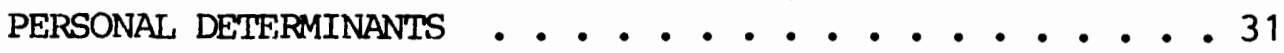

Attitude Toward the Act and Expectation of Outcome . . 32 
Increasing Pleasure and Decreasing Pain . . . . . 33 Low Self-Esteen . . . . . . . . . . 36 Low Value on and Expectation of Achievement . . . . 38 High Rebelliousness . . . . . . . . . . 38 High Adventuresomeness and Risk Taking . . . . . 39 Low Impulse Control - Low Delay of Gratification . • 39 High Independence ............. 40 Low Interpersonal Trust . . . . . . . . . 41 Gender Role Correlates . . . . . . . . 42

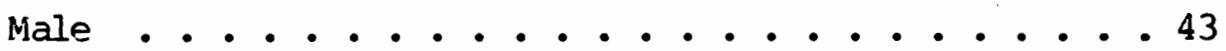
Female ...................... 46 Sunmary ............... . 449

V A MODEL FOR GROUP INTERVENIIION . . . . . . . . . 52 Introduction ............ . . 52 A Program for Group Counseling . . . . . . . 56 Session I: Developing Awareness of Group Functions and Defining Responsible Chemical Substance Use . . . 59

Session II: Identifying Coping Behaviors . . . . 61 Session III: Using Relaxation and Guided Fantasy as Coping Methods ............ 63

Session IV: Accepting Responsibility for Personal Behavior Choices . . . . . . . . . 66

Session V: Life Positions and Personal Control . . . 68 Session VI: Building Conmunication Skills . . . 70 Session VII: Enhancing Positive Self-Concept . . . . 72 Session VIII: Increasing Identified Strengths . . . 73 Session IX: Values and Lifestyle Choices . . . . 75 
CHAPTER

PAGE

Session X: Terninating the Group . . . . . . . 77 VI CONCLUSIONS AND RECOMMENDATIONS . . . . . . . . . 79 BIBLIOGRAPHY • . . . . . . . . . . . . . . . • . 86 APPENDIX • . . . . . . . . . . . . . . . . . . 94 


\section{LIST OF TABLES}

TABIE

PAG:

I Percent of Adolescents and Young Adults

Reporting Having Ever Used Marijuana: 1979 . . . . . . . 7

II Percent of Adolescents Reporting Ever Using Marijuana Prior to $10^{\text {th }}$ Grade: ............ 7

III Frequency of Marijuana Use .............. 7 


\section{CHAPTER I}

\section{INTRODUCTION}

\section{BACKGROUND}

Over the past twenty years young people increasingly have been turning to chemical substances for recreational purposes and as a means of coping with personal and environmental pressures. Frequency of use and abuse of chemical substances, especially marijuana spiral led during the late 1960's and early 1970's. This trend appears to have peaked around 1978 and there is evidence of slight moderation since that time (Johnston, Bachman, \& O'Malley, 1979a; Peterson, 1980).

Recognizing that adolescents were experimenting with chemical substances at younger ages, and using drugs more frequently, professionals from many disciplines proposed and initiated a variety of prevention, intervention, and treatment procedures, with varying degrees of success (Aubrey, 1973; Horan, 1974). Attention also centered on determining acute effects of chemical substances (Abel, 1971; Miller, Drew \& Kiplinger, 1972), and motivations underlying adolescent consumption patterns (Jessor, Collins \& Jessor, 1972; Kandel, Kessler \& Marqulies, 1978; Sadava \& Forsyth, 1976).

\section{PURPOSE}

This author's awareness of continued high rates of adolescent initiation to licit and illicit drug use, and the prevalence of daily 
chemical substance use, especially in the school setting, motivated her to do this study. The purpose of the thesis is to find consistent patterns in the research literature regarding: The extent of adolescent use and abuse of chemical substances, specifically alcohol and marijuana; the acute physical, psychological, and social effects of substance use/abuse; environmental determinants of use/abuse; behavioral - personal determinants of use/abuse; and, effective methods of prevention and intervention. Based on the research findings a model group counseling intervention program, designed for the school setting, is proposed.

It is imperative that mental health professionals and educators be aware of their own chemical substance use patterns, and of their personal biases or attitudes toward use by self and others. Lack of well defined standards may result in ambivalence, insincerity, or avoidance of the subject area. The potential for augmenting problem behavior is extremely high when counseling chemical substances users.

\section{LIMITATIONS}

In keeping with the current behavioral trend, the literature being examined is limited to relatively recent research, covering the past ten to twenty years. Because of use trend patterns, the focus of analysis and research included is limited to adolescent use of chemical substances, especially marijuana and alcohol. However, due to the limited number of studies using only high school and younger age groups, some research which uses college student samples is included. The emphasis of the analysis is on examination of deteminants of chemical substance use and abuse, and prevention and intervention possibilities. Although 
rehabilitation methods are mentioned, they are not explored in depth. Research chosen for reference within this study has been selected on the basis of empirical validity and methodological soundness.

\section{DEFINITION OF TERMS}

ABUSE: Is the misuse of any chemical substance in a manner which is manifest in substance-related physical, psychological, or social problems or disabilities (National Institute of Alcohol Abuse and Alcoholism, 1974).

ALCOHOLIC: One who is chemically dependent on alcohol (NIAAA, 1974). CHEMICAL DEPENDENCY: Usually this is defined as compulsive or uncontrolled consumption of the substance. Addiction to the drug is present, as is impairment of mental, physical, and/or social health (NIAAA, 1978).

CHEMICAL SUBSTANCES/DRUGS: Included are: alcohol (beer, wine, and hard liquor beverages), narcotics (rnarijuana, also spelled marihuana, hashish, cocaine), barbiturates, amphetamines, psychedelics, and opiates.

CURRENT USE: Is defined as having used within the past month (Peterson, 1980).

DAILY USE: Is defined as using the substance 20 or more times in the past 30 days (Johnston, 1979a).

EVER USED: Is defined as having ever tried a given chemical substance (Peterson, 1980).

HEAVY USER: One who habitually uses substances beyond social norms, in a manner which may sometimes lead to intoxication, but in circumstances that are tolerant to and appropriate for heavy use. No 
substance-related problems are evident (Worden \& Rosellini, 1981). PHYSICAL DEPENDENCE/ADDICTION: This usually refers to specific physiological disturbances that occur when chemical substance is withdrawn, and are alleviated when the substance intake resumes (NIAAA, 1978).

PROBLEM USER: One who uses the substance to an extent or in such a manner that a substance-related disability becomes manifest (NIAAA, $1974)$.

SOCIAL USER: One who uses a substance within a social setting. Very rarely does this use lead to misuse or intoxication. No substancerelated problems are evident (NIAAA, 1974).

TOLERANCE: Refers to the reduced effectiveness of a chemical substance after repeated intake. The body reguires increased amounts of a substance to reach a previous level of intoxication (NIAAA, 1978). 
EXTENT OF THE PROBLEM AND ACUTE EFFECTS

Past stereotypes of drug users as skid row bums, ghetto blacks, freaks and hippies are no longer realistic nor functional. Although marijuana use is significantly correlated with age (Peterson, 1980), in an examination of current use statistics Kandel (1980) reveals that "use of marihuana, tobacco, alcoholic beverages, and pills is consistently more prevalent among whites than among blacks..." and furthermore, "...rates of drug use (especially marihuana and alcohol use) among young people do not vary according to socioeconomic status (SES)..." (p. 246). Currently one in seven to ten adolescents use alcohol or marijuana on a daily basis.

EXTENT OF ALCOHOL LSE

By the senior year of high school nearly all adolescents have tried alcohol. Johnston (1977) surveyed a sample of adolescents concerning alcohol use and reported that ninety-three percent had used alcchol at least once, $71 \%$ of the respondents were current users, and $6.1 \%$ were dialy users. Modal grade of first use was ninth grade. With each succeeding grade in school, the proportion of drinkers and problem drinkers increase. Males show the largest increase between 7 th and 8th grades, while for females this occurs between 8th and 9th grade (NIAAA, 1978). Of the 7th grade class, 5\% of the boys and $4.4 \%$ of the 
girls were problem drinkers. By 12th grade, almost $40 \%$ of the boys and $21 \%$ of the girls were of the problem drinker category (NIAAA, 1978). A large difference in frequency of alcohol use between male and females is reported in Johnston's (1977) survey in which $29.4 \%$ of the males reported use of alcohol forty or more times in the last year, while only 14.1 \% of the females reported this frequency.

More than at any other point in the lifespan, the adolescent and young adult is susceptible to experiencing "...negative consequences associated with the acute effects of alcohol..." (NIAAA, 1978, p. 17). Farly drinking patterns often are predictive of drinking habits which develop later in life.

\section{EXTENT OF MARIJUANA USE}

National Institute of Drug Abuse reports indicate that in 1979, 8\% of the 12-13 year olds surveyed had tried marijuana. Of the 14-15 age bracket, $32 \%$ had used the drug, and of the 16-17 age group, 51\% had tried marijuana (Table I). Compared with statistics gathered fram a similar study in 1972, the percentage of 12-17 year old adolescents who had ever used marijuana had doubled by 1979, fram $14 \%$ to $31 \%$ (Table III). Concurrently, the percentage of all youth who had used marijuana prior to 10th grade increased from $16.9 \%$ in 1975, to $30.4 \%$ in 1979 (Table II).

Of those who reported ever using marijuana in 1979, about half indicated current use. Taking the 12-17 year old group as a whole, $16.7 \%$ currently use marijuana, a substantial increase over the $7 \%$ reported for this same category in 1972.

Daily use rates in 1979 stood at 10.3\%, up from 6\% reported in 
TABLE I

PERCENT OF ADOLESCENTS AND YOUNG ADULTS REPORTING HAVING EVER USED MARIJUANA: 1979

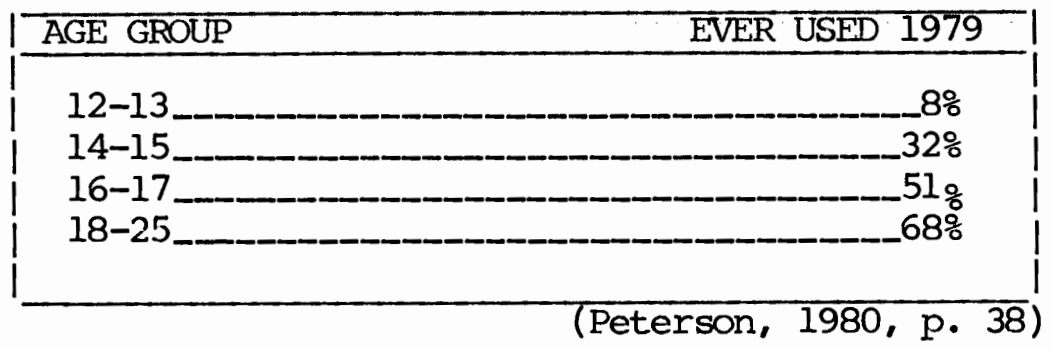

TABLE II

PERCENT OF ADOLESCENTS REPORTING EVER USING MARIJUANA PRIOR TO 10th GRADE

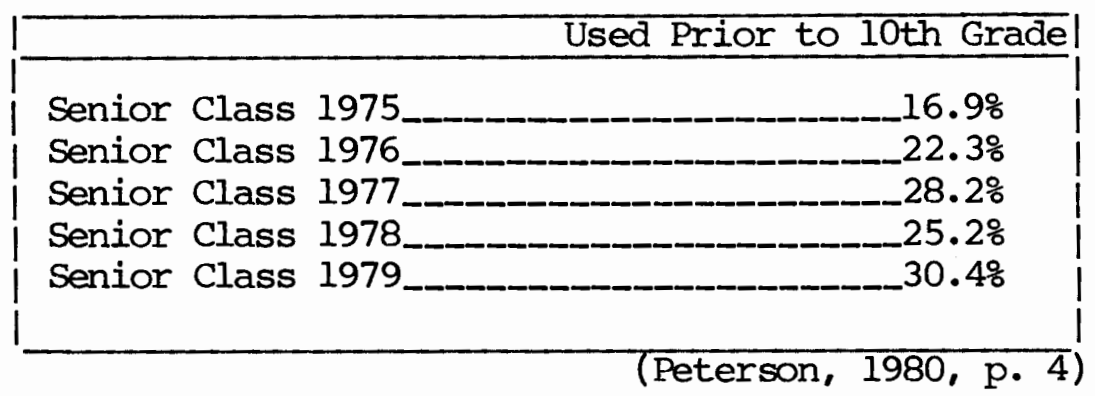

TABLE III

FREQUENCY CF MARIJUANA USE

\begin{tabular}{|c|c|c|c|c|c|c|}
\hline Age Group & \multicolumn{2}{|c|}{ Ever Used } & \multicolumn{2}{|c|}{ Current Use } & \multicolumn{2}{|c|}{ Daily Use } \\
\hline & 1972 & 1979 & 1972 & 1979 & 1975 & 1979 \\
\hline $12-17$ & $14 \%$ & 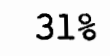 & $7 \%$ & $16.7 \%$ & $6 \%$ & $10.3 \%$ \\
\hline $18-25$ & $48 \%$ & $68 \%$ & $25 \%$ & $35 \%$ & $\mathrm{~N} / \mathrm{A}$ & $\mathrm{N} / \mathrm{A}$ \\
\hline
\end{tabular}


1975 (Table III). The 1981 high school senior survey conducted by Lloyd Johnston indicates a moderation to $7 \circ$ in daily marijuana use (The Columbian, 1982). Unfortunately, these surveys do not ascertain how much marijuana is consumed at any one time (Kandel, 1980).

While the overall use of alcohol exceeds that of marijuana, daily use of marijuana in 1979 exceeded that of alcohol. Of adolescents surveyed, over $10 \%$ used marijuana daily as compared to $7 \%$ who used alcchol on a daily basis (Johnston, Backman, and O'Malley, 1979a).

\section{EXTENT OF MULTIPLE DRUG USE}

From the 1930's to 1950 's the Federal Bureau of Narcotics directed a spurious propaganda campaign against marijuana use by declaring that smoking marijuana would lead to the use of other dangerous drugs. Known as the stepping stone hypothesis, proponents argued that using marijuana ultimately would lead to heroin use and addiction (Eisterhold, Murphy, Beneke, \& Scott, 1979; Grinspoon, \& Bakalar, 1978). Although recent research confirms that people who use other illicit drugs generally have used marijuana as well, the evidence does not support a causative progression from marijuana to other drug usage (Gould, Berberian, Kasl, Thampson, \& Kleber, 1977). The research of Single, Kandel, \& Faust (1974) indicates there is a strong association between marijuana use and the use of other illicit drugs. More frequent and regular use of marijuana was found to be highly correlated to mutiple drug usage. However, Single and associates stress that their data "...do not show that the use of marihuana leads to the use of other drugs... But the use of other drugs rarely takes place in the absense of 
experimentation with marihuana" (p. 350).

Social acceptance of alcohol appears to condone adolescent use of beer, wine, and liquor as more preferable than illicit drug usage. Although the use of alcohol by adolescents far exceeds that of marijuana, 90 to 94 percent of illicit drug users have also used alcoholic beverages. Thus, if there is a progression in drug usage, the first drug appears to be alcohol (Single et al, 1974).

While serial evolution of multiple drug use cannot be attributed to the drugs directly, there appear to be important behavioral patterns in the multiple drug using population. Fron a comprehensive study of over 1,000 high school students Gould and associates (1977) outlined the following sequence and pattern of multiple drug consuming behavior:

...first cornes alcohol, next marijuana, and then hashish. those who progress beyond hashish are about equally likely to go to barbiturates, amphetamines, LSD, or mescaline. The respondents in our sample did not in most cases progress beyond these four drugs, however, unless they had used all four of them. Then, the progression was to heroin and cocaine, in that order, for those who used heroin, or directly to cocaine for those who did not use heroin. (p. 222)

Among those adolescents who used marijuana, Single, et al., (1974) found the following rates of multiple drug usage: Hashish (718), amphetamines $(44 \%)$, barbiturates $(40 \%)$, cocaine (13\%), and heroin (9\%), (p. 347). Contrary to what might be expected, consumption of alcohol did not decrease as use of marijuana increased. "Daily use of hard liquor increases in direct proportion to the frequency of current marijuana use...daily use of hard liquor is 16 percent among daily marijuana users..." (p. 349). 
ACUTE EFFECTS OF ALCOHOL

Because alcchol has been a socially used substance over the centuries, and a focus of empirical study during the 20th century, there is a great deal of documentation about alcohol's acute effects on human functioning (NIAAA, 1978; Seixas, 1972). In studying problems of drug usage it is helpful to examine physical, cognitive and social deterioration as acute effects of alcohol.

\section{Physical Effects}

"Alcohol has a pervasive effect on the body from its point of entry through the gastrointestinal tract, the liver, and throughout the bloodstream. The brain and nervous system, heart, muscles, and endocrine system are also affected" (NIAAA, 1978, p. 37). There appears to be a link between alcohol use and cancer. Risk of cancer at different sites in the body increases with alcohol consumption. In combination, alcchol and tobacco have a synergistic effect enhancing the risk of certain kinds of cancer (NIAAA, 1978).

Psychomotor responses are altered dramatically in people who are under the influence of alcohol. These abilities, which are especially necessary when driving or flying, include: "...visual functions of glare recovery, light adaptation, detection of objects in the peripheral visual field, and visual search" (NIAAA, 1978, p. 54).

Fetal alcohol syndrome (FAS) is clinically observable in cases where the mother consumed alcohol during pregnancy. The characteristics of the mother's alcohol use and the stage of embryonic development appear to make a difference in producing the FAS (NIAAA, 1978). 
Cognitive Effects

While alcohol does not impair ability to concentrate attention on one source of information at a time, it does appear to "...impede the brain's capacity to switch from one source of information to another", and to "...absorb information from more than one source simultaneously" (NIAAA, $1978 \mathrm{p} .53$ ). Significant loss of memory functions occurs in both alcoholics and nonalcholics when intoxicated. While the nonalccholic individual experiences a memory loss after consumption of smaller amounts of alcohol, the effect is similar to the alcoholic blackout, "...amnesia without loss of consciousness..." (NIAAA, 1978).

As it is with marijuana, "memory storage processes are particularly vulnerable to disruption by alcohol. When intoxicated, people have considerable difficulty processing new information and recalling that information later" (NIAAA, 1978, p. 53). Research now is finding that alcohol consumption may cause lingering impairment of cognitive functions. Serious impainment is noticeable in sober alcoholics, and it appears that social drinkers also are vulnerable. In a study of male social (nonproblem) drinkers "performance on tests of abstractions and adaptive abilities [while sober] showed a significant negative association with the amount of alcohol the men reported consuming" (NIAAA, 1978, p. 54).

\section{Social Effects}

Because alcohol consumption disrupts mernory processes and other cognitive functioning, we may assume that adolescents who attend school while intoxicated are likely to suffer academically. High school students who use alcohol have been found to achieve below their potential 
(Lawrence \& Velleman, 1974). The cause of low achievement may also be explained by the students' self-expectations. Jessor, Caman, and Grossman, (1968) suggest that students with low expectations of their ability to achieve academically or socially tend to drink, get drunk, and become problem drinkers more often than students with higher selfexpectations.

The social ramifications of alcchol use/abuse are as pervasive as alcohol's destruction of the individual physical being. At least $50 \%$ of all traffic-related deaths and over $30 \%$ of traffic-related injuries are tied to alcohol consumption. Industrial accidents, drownings, fire fatalities, and fatal falls all are significantly related to alcohol intoxication (NIAAA, 1978).

Alcohol also is significantly associated with crime, family violence, and suicide. "More than one-third of all suicides involve alcohol, and disproportionately high numbers of people with drinking problems cormit suicide...accidents and violence play an especially prominent role in death and injury among the younger age groups" (NIAAA, 1978, pp. 65-66). Recent research has focused attention on the high correlation between excessive alcohol consumption and spousal battering (Miller, 1979), and child molestation and abuse (NIAAA, 1978).

Dysfunctional family interaction patterns develop in the presence of alcohol misuse by any family member. Through counseling of chemically dependent clients, Wegscheider (1979) has found "in a family where there is stress, the whole organism shifts to bring balance, stability or survival" (p. 3). Family members adapt in ways which create less personal stress. 
Because of the system balance, each nember of the family begins to respond to the dependent from a double level position. Family members, like the dependent, begin to repress their feelings and also develop a set of defenses to protect them from further pain... As the compulsion grows between the dependent and the chemical, so does the compulsion grow between the dependent's behavior and the family's reaction. (Wegscheider, 1979, pp. 5-6)

When an adolescent is the problem drinker, other social systems also respond and react. Adolescent drinking behavior which warrants action from school and public law officials will activate an array of consequent social ramifications which are likely to have a substantial impact on the adolescents' future.

\section{ACUTE EFFECT OF MARIJUANA}

Physical Effects

Research studying the effect of marijuana on the human cardiovascular system, immune response, chromosome abnormalities, cell metabolism alterations, and brain darage, remains equivocal (Peterson, 1980). Although there is some indication that chronic, heavy marijuana use may bring about cannabis dependency, the data is too limited to be conclusive (Jones, 1977; Jones \& Benowitz, 1976). There is substantial evidence, however, that tolerance to marijuana develops with prolonged use (Jones \& Benowitz, 1976; Nowlan \& Cohen, 1977). Because marijuana metabolites concentrate in fatty tissue, remaining in the body for long periods of time, they may be passed through the placenta of expectant mothers and also be present in the mother's milk. Although the data is still limited regarding this possibility, there is enough evidence to caution against marijuana use during pregnancy and while nursing infants 
(Peterson, 1980).

Recent studies continue to link marijuana smoking with lung damage (Rosenkrantz \& Fleishman, 1979), impaired psychomotor coordination (Klonoff, 1974), and alterations in reproductive functioning (Hembree, Nahas, \& Huang, 1979; Sassenrath, Chapman, \& GoO, 1979).

\section{Cognitive Effects}

Marijuana users may experience acute anxiety or transient mild paranoia. The anxiety response occurs generally with experienced users who consume unusually high doses, or with inexperienced users who lose perspective of the experience being drug induced. Feelings of paranoia, common among users, are influenced by the individual's expectations and the environment in which the drug effect is experienced (Peterson, 1980).

While it appears that "...marihuana does not significantly interfere with the retrieval of information already present in the memory" (Abel, 1971, p. 1031), marijuana use does impair the user's short-term memory functions. Abel suggests that it is the person's inability to concentrate and rehearse which prevents information being transfered to permanent memory. Rossi \& O'Brien (1974) contend that this might reflect what the marijuana intoxicated subject chooses to attend to. Miller \& Drew (1974) speculate that the effects of marijuana on memory may be due to impainment of limbic structures in the brain. In earlier research, Miller, Drew, \& Kiplinger (1972), found that subjects could not recall specific material, and also tended to introduce material which was not suggested originally.

The specific etiology of marijuana induced impaiment of short- 
term memory function continues to receive empirical examination. What is relevant to mental health professionals and educators is that "...material learned while 'high' is significantly less well recalled than that learned in a nondrugged state. This is especially true when the task involves recalling the learned material rather than simply its recognition" (Peterson, 1980, p. 10), which suggests that students who attend classes while high are likely not to process information into long-term memory or to recall and utilize material already learned. Low to moderate levels of marijuana intoxication creates the sensation of speeding up subjective, internal time relative to objective, clock time so that time seerns to pass more slowly. Higher doses of marijuana tend to induce a sense of timelessness (Melges, Tinklenberg, Hollister \& Gillespie, 1971). Furthermore, marijuana intoxication causes confusion of past, present and future orientation, leading to a decrease in goal-directed thinking (Clark, Hughes, \& Nakashima, 1970). Further study reveals that "...marijuana induced significantly greater concentration on the present...to the relative exclusion of past and, in particular, future references" (Melges et al., 1971, p. 565). In summarizing the effects of marijuana on changes in time sensations Melges and associates (1971) state:

Under the influence of marihuana, when a subject becomes less able to integrate past, present, and future, his awareness becomes more concentrated on present events; these instances, in turn, are experienced as prolonged or timeless when they appear isolated from the continual progression of time - that is, when the present events no longer seem to be transitions from the past to the future. (p. 566)

The effects of marijuana apparent in the time distortion and memory functions, helps to explain the "amotivational syndrome" described 
by Kolansky and Moore. From their psychiatric practice (Kolansky and Moore, 1971) they correlated current marijuana smoking with patients' "...poor social judgment, poor attention span, poor concentration, confusion, anxiety, depression, apathy, passivity, indifference, and often, slowed and slurred speech" (p. 487). The amotivational syndrome was proposed as an organic cognitive syndrome which encompassed acute physical, cognitive, and social effects. While the concept continues to surface in the literature, the study has been discredited as a scientific work due to lack of a prospective design and obvious methodological flaws (Grinspoon \& Bakalar, 1978).

\section{Social Effects}

No experimental studies which directly assess the impact of marijuana intoxication on classroom learning have been reported in the recent literature. Different researchers' accounts of achievement levels of marijuana users are inconsistent. Smart and Fejer (1969) characterized marijuana users as underachievers, while Stefferhagen, McAree, \& Zheutlin (1969) found them to be somewhat above average academically, and Pearlman (1968) found no difference between users and nonusers' academic performance. These earlier studies were of college samples and reflect characteristics not necessarily present in a junior high or high school population.

Investigation of high school marijuana users reveals that students "...tend to achieve below their potential in school..." (Lawrence \& Velleman, 1974, p. 135), and that "...low expectations for achievement, [are]...significantly related to marijuana involvement in the junior 
and senior high..." populations, but not at the college level (Jessor, Jessor, \& Finney, 1973, p. 14). According to a survey done by The Merit Publishing Company" ...10\% of high achieving students have tried marijuana" (Yancy, Nader, \& Burnham, 1972, p. 743). However, in their study of high school marijuana users, Victor, Grossman, \& Eisenman (1973) found that "...as the frequency of marijuana use increased, there was a significant decrease in reported scholastic averages across all grade levels..." (p. 83).

Lack of future goal orientation, and low delay of gratification associated with heavy marijuana use, may inhibit productive involvement in work, commmity, and social activities. The long term social effects of current high rates of drug use by today's adolescents are yet to be seen.

Because use of licit and illicit drugs is regulated by federal and state laws, adolescents using or abusing substances are subject to legal prosecution for their drug using activity. Age restrictions and penalties for use of both licit and illicit drugs vary, thus the social and personal ramifications to the user are different from state to state. The impact of a criminal (felony or misdemeanor) record upon the future of adolescents cannot be ignored. 
MOTIVATION FOR CHEMICAL SUBSTANCE USE: ENVIRONMENTAL DETERMINANTS

Adolescent motivation for arug use and abuse will be examined fram the social learning framework. From this perspective behavior is motivated by a continuous reciprocal interaction of environmental and personal determinants (Bandura, 1977). For the purpose of understanding specific systems involved in the interaction process, this study will examine environmental determinants and personal determinants separately. The reader is cautioned to bear in mind that in the process of life, environmental and personal systems continually interact and change. No one aspect herein discussed is suggested as an independent motivator for chemical substance use or abuse.

\section{REINFORCEMENT AND MODELING}

External systems influence individual perceptions and behavior by processes of reinforcement and modeling. According to Bandura (1977), consequences to particular behavioral responses impart information, provide incentive value, and may strengthen responses automatically. Cues in the environment may signal upcoming occurrences or predict outcomes from particular actions. "For the most part, response consequences influence behavior antecedently by creating expectations of similar outcames on future occasions" (p. 96).

Modeling is a process of learning through observation. No direct performance or extrinsic reinforcement of behavior is necessary, only 
exposure to the modeled activities. What will be observed will be influenced by being perceived as rewarding (Bandura, 1977).

As will be discussed more fully in Chapter 4, the individuals' beliefs regarding external events influence their behavior. "Identical environmental consequences can have different behavioral effects depending on beliefs about why they occur" (Bandura, 1977, p. 166). From his research, Bandura concludes that beliefs about current conditions of reinforcement will outweigh the influence of experienced outcones. The environment is a potential which responds to the persons' actions, and environmental systems impact the development of personal belief structures. Akers, Krohn, Lanza-Kaduce, \& Radosevich, (1979) summarize the social learning process:

Whether deviant or conforming behavior is acquired or persists depends on past and present rewards or punishments attached to alternative behavior - differential reinforcement. In addition, people learn in interaction with significant groups in their lives evaluative definitions (norms, attitudes, orientations) of the behavior as good or bad... which can be directly reinforced and also act as cue (discriminative) stimuli for other behavior... the reinforcers can be nonsocial (as in the direct physiological effects of drugs) as well as social, but...the principal behavioral effects come from interaction in or under the influence of those groups which control individuals' major sources of reinforcement and punishment and expose them to behavioral models and normative definitions. (Akers et al., 1979; in Kandel, 1980, p. 253)

Historical Perspective and Social Influences

Man's social-recreational use of cannabis and alcohol date back 5,000 and 6,000 years respectively (Arnao, 1976). Whether for medical, religious, or social reasons, American culture has sanctioned using certain drugs in crtain circumstances. Social attitude toward alcohol use 
traditionally is associated with religious, moral and ethical values.

Yet:

As these more general beliefs and values vary among individuals and among population subgroups, and as they fluctuate over time, those that are connected with alcohol use have been carried along in a haphazard fashion. The net result is that the public is left with a melange of ambivalent feelings about drinking and...there is a vast pool of ignorance about what constitutes responsible drinking... (NIAAA, 1974, p. 22).

Confusion and argument regarding realistic standards of alcohol consumption has contributed to overuse and abuse of the drug. Alcoholism often is not recognized until it is well established, and alcoholic denial is facilitated as a result of controversial social definition of responsible drinking behavior.

With the exception of the Prohibition years (1919 to 1933), alcohol has enjoyed a position of acceptance as a social drug in American culture. While marijuana currently is subject to legal sanctions, increasingly it is rising in popularity for social-recreational purposes. If: "Social control may be defined as the process by which a society shapes the behavior of the individual member toward the group norms of society" (Roucek \& Roland, 1965, p. 291), then: "It is societal reaction either directly or indirectly, that largely defines deviant behavior" (Hunt, 1974, p. 273). Societal reaction to marijuana use defined it as a deviant behavior in the late 60's and early 70's. Today, as experimentation with the drug is modal by age 16-17, this response may no longer be appropriate.

Americans consume volumes of over-the-counter drugs, self-medicate with prescribed drugs, and seek comfort through drugs with little hesitation (Aubrey, 1973). Furthemore, national advertising on 
television, radio, in magazines and in newspapers reinforce drug usage by supplying cues, anticipation of outcomes, and social approval simultaneously. This multitude of reinforcing cues, and the wealth of role models, combined with sociocultural ambivalence toward standard setting, creates a milieu conducive to chemical substance use and abuse by adolescents and adults alike.

\section{Religious Affiliation}

Several studies have correlated religious involvement with drug use or abstinance. It is likely that greater religiosity and church attendance predispose adolescents against drug use (NIAAA, 1978). Graham \& Cross (1975) proposed that nonusing adolescents were not strongly religious in orientation but that users were strongly anti-religious. Recently Eisterhold and associates (1979) found "religious activity was not significantly related to the frequency of beer or wine use but did have a significant relationship with both hard liquor use...and marijuana use..." (p. 1104) among high school students.

Different religions have established different norms for alcohol consumption. The Mormon and ascetic Protestant religions are 'proscriptive' while the Jewish faith is 'prescriptive' regarding drinking behavior (Braucht, Brakarsh, Follingstrad, \& Berry, 1973). While proscriptive norms do not allow any alcohol consumption, prescriptive norms set up an "...elaborate system of explicit directives as to what, when, where, with whom, how much, and why one is expected to consume alcoholic beverages..." (Braucht et al., 1973, p. 93). On the surface, affiliation with religions holding prescriptive beliefs regarding alchol use may appear to dispose the individual to greater use of 
alcohol. However, the nonns established by the religion would seem to help safeguard against misuse and abuse of the drug. While fewer followers of religions having proscriptive beliefs actually drink alcohol, those that do are more likely to become problem drinkers. This is because "...there is an absence of norms to guide their use, [thus]...the drinking is more likely to be uncontrolled" (Braucht et al., 1973, p. 94).

Parental Influence

The majority of adolescents have their initial alcohol experience with parents or relatives, in the home environment (Braucht et al., 1973). Parental modeling, and family interaction patterns have a significant impact on the adolescent's cognitive and behavioral representation of nomative definitions and differential reinforcement. While only $2 \%$ of adolescents reported parents who use marijuana, Eisterhold and associates (1979) found only 16\% reported parents who did not use alcohol. Parental use of these drugs was significantly related to the child's use of the same drug. Kandel (1980) reports that "parental use of hard liquor predicts adolescent use of hard liquor and other illicit drugs but not marijuana. Parental use of psychoactive drugs predicts adolescent use of illicit drugs other than marijuana..." (p. 271)

The manner in which parents consume alcohol appears to have some impact on their children's chemical substance use. Lawrence and Velleman (1974) found:

No significant association... between how often each parent drinks and the student's drug use. Significant relationships do exist between how many drinks each parent has 
when he drinks and students' drug use...The strongest associations were found with how often a parent was drunk. (p. 131)

It is possible that parental drinking may be most accurate in predicting adolescent drinking and other substance using behavior (Braucht et al, 1973; Kandel, 1980; Lawrence \& Velleman, 1974). In a home envirorment which has not defined or does not adhere to responsible drug using behavior, children learn to misuse and abuse chemical substances. Because parental influence operates as only one of many environmental factors impacting the adolescent's belief structure, even socially responsible use of alcohol and other drugs may be perceived as a model for other chemical substance experimentation (Mercer, Hundleby, \& Carpenter, 1978).

Parental modeling affects help shape the child's values, attitudes and behavior. In addition, the atmosphere created in the family unit, and the behavior of the parents toward the child shape personality and behavior. Parental warmth, support and interest has been shown to relate significantly to adolescent drug use (Mercer et al.. 1978; Rosenberg, 1969). Babst, Deren, Schmeidler, Lipton \& Dembo (1978) suggest that "...the less close a student feels toward his family, the more likely he is to be involved with friends who use drugs" (p. 37). The authors also note that multiple drug use increases relative to a decrease in family affinity. Tudor, Petersen, \& Elifson (1980) support this finding: "the closer the adolescent is to his/her parents, the less the likelihood of drug use" (p. 789). In her review, Kandel (1980) concludes:

The quality of the parent child bond is assumed to have a restraining effect on involvement in deviant and delinquent attitudes, irrespective of parental behaviors and 
values" (p. 256).

Studies conducted by Graham \& Cross, (1975) reveal that drug using adolescents "...felt rejected at home, that their parents did not trust them or genuinely care about them, and that there was little to talk about in conmon with their parents" (p. 104). Kandel (1980) cites low parental aspirations for children as predictive of marijuana initiation, and suggest a lack of perceived parent-child closeness is predictive of what she defines as the "...third stage of drug involvement, initiation to drugs other than marijuana..." (p. 271). Gantman (1978) found that parents of drug abusing adolescents engage in increased scapegoating of the child, and utilize negative and unclear communication styles which exhibit insensitive and unequal interaction patterns. In examining the perceived parental permissiveness of a college sample relative to the degree of marijuana usage, Hunt (1974) sought to establish the degree to which parental use of social control determines the offsprings involvement with marijuana. His findings indicate: 1) high use of marijuana in offspring of perceived laissez-faire child-parent relationship; 2) medium use of marijuana in of fspring of perceived autocratic child-parent relationship; and, 3) low use of marijuana in offspring of perceived quasi-democratic or democratic child-parent relationship. In this study laissez-faire parents were found to reflect a lack of interest in, and relinguish responsibility and authority over their children, while the autocratic parents are over-controlling, demanding and intolerant. Both parenting styles create a family enviromnent which may encourage the adolescent to seek alternative means of providing a warm, understanding 'family type' atmosphere. Membership in a marijuana using group fills many of these affiliation needs. Democratic and 
quasi-democratic styles allow for optimum parent-child interaction. The child's participation is solicited and respected. Mutual sharing and listening fosters personal commitment. While the parents may remain as the "final word", children perceive they have been heard and that their parents care.

Studies have identified differences in adolescent drug use based on both the adolescent's and the parent's gender. Mercer \& associates found a stronger correlation between family enviroment and adolescent female drug usage than adolescent male drug usage. Brook, Lukoff, \& Whiteman (1980) determined that adolescent marijuana initiates:

[are]...more likely to have mothers who have low expectations for them, are not involved in activities with them, are nonconventional, and passive. Moreover, initiates are likely to have mothers with an internal orientation, accompanied by low expectations. (p. 140)

Frankel, Behling, \& Dix, (1975) noticed a difference in the adolescents' perceived relationship with their fathers. Here, the heaviest drug using adolescents perceived their fathers as being cold and distant. However the mother's warmth was not significantly related to drug use frequency.

Lack of loving care and closeness between parent and child appears to set the stage for adolescent perception of drug use as positive and rewarding. Severely impaired communication and the absence of wam interpersonal child-parent relationships creates a high risk situation for adolescent multiple drug use and abuse.

Peer Influence

The evidence is conclusive that peer support and instruction is responsible for a substantial percent of initial adolescent marijuana 
use (Adler \& Lotecka, 1973; Kandel, 1973; Lawrence \& Velleman, 1974; Sadava \& Forsyth, 1977). Eisterhold and associates (1979) found "fiftytwo percent of the $42.6 \%$ [of students] who reported ever using marijuana did so at the suggestion of a friend who provided them with the drug" (p. 1104). Lucas (1978) determined that "...having frequent contact with close marijuana-using friends..." was one of five variables which "...explained more than 558 of variance in initial marijuana use" ( $p$. 1038).

In their longitudinal study Jessor, Jessor, \& Finney (1973) found that adolescents who use drugs perceive less compatibility between parents and friends regarding values and expectations for the actor. This research reveals adolescents perceive "...greater peer-relative-toparent influence on thier views...[and] greater models, pressures, and peer approval for drug use" (p. 6-7). Of the environmental measures employed, the peer-relative-to-parent influence was most predictive of male drug use, while social support for drugs was most predictive of female drug use. Empirically, "...social support for drug use...turned out to be its most powerful predictor" (p. 13).

Kandel (1980) stresses that "friends' behaviors are especially important in predicting marihuana use and relatively less important for predicting drinking or the use of illicit drugs other than marihuana..." (p. 270). However, Jessor et al., (1972) maintain that peer reinforcement and instruction is instrumental in predicting change from abstainer to drinker in junior and senior high school students.

Peer support of drug use also influences the adolescents decision to continue use after initiation. Johnson (1973) held that young people who use marijuana seek other marijuana users as their friends and 
disassociate themselves from other non-user friends. Citing Britt and Campbell (1977), Kandel (1980) notes, "the selection as significant others of persons perceived to be like the self may be more important than the effect of perceived group norms to the production of behavioral and attitudinal similarity..." (p. 262). Membership in a drug using peer group either before or after initiation to drug use will depend in part on internal personal factors, saliency of peers to the individual, and perceived differential reinforcement. Nevertheless, for the most part, drug users associate with one another. In the majority of cases a peer support system influences the individual's first use of drugs and it appears that "...becoming involved in one of these support systems...serves to reinforce the act of drug-taking..." (Huba, Wingard, \& Bentler, 1980, p. 277). Current marijuana users most frequently consume within a group of one to three friends (Eisterhold et at., 1979). Similarly, "...peers are the adolescents' most typical drinking companions" (NIAAA, 1974, p. 19).

While peer influence is an active agent of initiation and continuation for both marijuana and alcohol use, "there appears to be different support systems for alcohol and cannabis use...suggesting different drug use support cultures" (Huba et al., 1980, p. 275-276). Kandel (1980) suggests that "...the data supports the notion of drug-specific social networks of peers, each oriented towards a particular drug. Prior association with users of a particular drug is the strongest predictor of an individual's use of that drug..." (p. 270). Furthermore, social configurations within high school communities continues to be drawn on drug related lines (Lawrence \& Velleman, 1974).

Scherer, Ettinger \& Mudrick (1972), studying adolescents who used 
other drugs in addition to alcohol, marijuana and hashish, found this group indicated a high need for social approval. Eighty-six percent of the multiple drug users surveyed were initiated into use through friends. The researchers suggest that "...social pressure may...produce drug use among those with a high need for social approval [because]...hard-drugoriented peer groups offer greater opportunity for gaining approval, simply by adherence to hard drug usage" (Scherer et al., 1972, p. 12). In discussing the single criterion most predictive of polydrug use, Sadava \& Forsyth (1977) found social support to be first and highest in loading. Representative of social support were variables from the proximal environment including "...high social support for use, absence of sanctions against use, availability of drugs, [and] parental and peer models of use..." (p. 219). Clearly adolescent peer support systems are extremely influential to establishing initial drug use and subsequent chemical substance involvement.

\section{School Influence}

Attitudes and beliefs fostered in the home environment appear to translate (be sustained) into the school environment as well. Babst et al., (1978) found that $30 \%$ of adolescents from low affinity families, compared to $70 \%$ of youth from high affinity families were interested in school. Average grades in school decreased relative to decreases in family affinity. Moreover, Graham \& Cross (1975) noted that adolescent drug users who described their home relationships as negative and ermpty:

...also perceived a lack of concern on the part of school officials and faculty over whether they used drugs, attended class, or in general abided by the school regulations. 
Apparently, the users felt the atmosphere around the school was such that they could do as they pleased and no one would care much about it as long as they did not start trouble for someone else. (p. 104)

Response to drug use within the schools has been characterized by by the same two extremes found in family structures, the laissez-faire attitude, and the autocratic or authoritarian response. In this latter mode, known drug users are suspended or expelled from school and often are turned over to law officials. An attitude of intolerance and militance is maintained. The 'law and order' response, while temporarily removing the problem person from the school, does not solve the underlying problem. As Bearden, Woodside, \& Jones, (1979) note:

...efforts to affect drug use which focus on availability and criminal deterrence may be ineffective since these are not the considerations which affect motivations to use drugs. (p. 749)

If fear of legal punishment is unrelated to student drug use (Lawrence \& Velleman, 1974), then school policies based on legal sanction and punishment are destined to frustration and ultimate failure. While Hunt's (1974) study of social control through leadership style focuses on parenting, it would appear that the principles apply to schools' 'in loco parentis' responsibilities as well.

In addition to setting an envirormental tone of laissez-faire or autocracy, schools have responded to the drug problem with their most available tool, education. Unfortunately, the subject matter has not been one which easily or successfully responds to the format of classroom instruction. Various approaches to drug education have been tried. Many aimed at integrating drug education into the school curriculum. The liajor drawback to these attempts was the mistaken belief that "...large doses of factual material would deter youngsters from experimenting with drugs" 
(Aubrey, 1973, p. 26). Scare tactics such as 'horror' movies and incorrect or misleading information about drugs succeeded only in reducing the schools credibility with students (Horan, 1974). Later attempts to be relevant and up-to-date were suspected to have augmented student curiosity, and the use of ex-addicts in school assembly presentations, while sensational, were of negligible benefit (Aubrey, 1973; Lawrence \& Velle$\operatorname{man}, 1974)$. In trying to respond to public concern, schools were not prepared to address the drug use problem effectively. As Aubrey (1973) points out, "by relying on traditional approaches the schools showed a lack of understanding as they attempted to meet an affective problem with cognitive procedures" (p. 27). However, out of all the good intentions and poor results, much has been learned in the field of drug education, and will be discussed more fully in Chapter Five.

\section{SUMMARY}

Modeling effects and differential reinforcement of behavior occurs through interaction with parents, peers, significant others, and sociocultural institutions. The most salient of these to adolescent drug involvement appears to be parents and peers. Of the environmental variables, high peer support is most predictive of initiation to marijuana usage while parental use or abuse of alcohol or psychoactive drugs is most predictive of the child's initiation to alcohol and illicit drugs other than marijuana. Lack of warmth and equity in family communications, extremes of laissez-faire or autocratic social control styles, poorly defined standards of appropriate drug using behavior, abundant abusing role models, and peer support systems all contribute to an atmosphere conducive to drug use, abuse, and dependence. 
MOTIVATION FOR CHEMICAL SUBSTANCE USE: PERSONAL DETERMINANTS

Substantial research and argument has centered around the question of a genetic predisposition to progressive alcohol dependence (Goodwin, Schulsinger, Hermansen, Guze and Winoker, 1973; Kaij, 1960; Omenn \& Motulsky, 1972; Partanen, Bruun, \& Markkanen, 1966; Siexas, 1972). The available data indicates that continued research into the concept of genetic predisposition is warranted. However, physiological factors of inheritance necessarily begin to interact with environmental forces at birth, and perhaps before. People are born with many different possible inherited predispositions. How that inborn potential grows and expresses itself will be shaped by the reciprocal interaction of personal, environmental, and behavioral responses.

Personal determinants of behavior include thoughts, feelings, and perceptions about behavioral outcome and environmental conditions. Cognitive factors partly determine which external events will be observed, how they will be perceived, whether they leave any lasting effects, what valence and efficacy they have, and how the information they convey will be organized for future use. (Bandura, 1977, p. 160)

Expectations of outcomes influence one's behavior, and reciprocally, actual outcomes change one's expectations. Attitudes toward the actions one takes, or contemplates taking, are formed on the basis of one's expectation of the action's outcomes. From his research Bandura (1977) asserts: 
Beliefs about the prevailing conditions of reinforcement...[will outweigh] the influence of experienced consequences... As people are exposed to variations in the frequency and predictability of reinforcement, they behave on the basis of the outcomes they expect to prevail in the future. (p. 166)

Thus, beliefs about expected outcomes of behavior will shape attitudes toward engaging in that activity. These "cognitive representations of future outcomes function as current motivators of behavior" (Bandura, 1977, p. 161).

ATTITUDE TOWARD THE ACT AND EXPECTATION OF OUTCOME

In their early prospective research Jessor et al., (1973) and Sadava (1973a, 1973b) determined that attitudes toward the act, and expectation of outcomes are predictive of initial chemical substance use. According to Fishbein and Ajzen's (1975) theoretical model, intention to engage in a behavior is conceptualized as a combination of attitude and subjective norms. Attitudes toward engaging in specific behaviors are determined by one's perception of the consequences (cook, Lounsbury \& Fontenelle, 1980). Bearden, Woodside, \& Jones (1979) describe the cognitive interaction of attitude, expectation of outcome, and the subjective norm factor:

Attitudes toward engaging in a particular behavior are assumed to be a function of the summation of the individual's beliefs and evaluations regarding the salient outcomes of engaging in that behavior. Social norm is depicted as a summed function of the individual's beliefs concerning the expectations of his relevant referent groups weighted by his motivation-to-comply with those expectations. (p. 745)

Using the Fishbein and Ajzen model, Cook and associates (1980) concluded that the adolescents' "attitude toward the act was the best predictor of marijuana and beer use. The subjective noms variable 
added significantly to the prediction of these two drugs" (p. 199).

In a four year longitudinal study Lucas, Grupp, \& Schmitt (1975) determined that expressed desire to try marijuana, holding attitudes favorable to marijuana use, and the presence of available opportunities to try marijuana were statistically significant predictors of initiation to marijuana use (p. 323). The authors conclude that the possession of a favorable attitude toward use, and an expressed desire to use marijuana is an indication that the individual has internalized a value structure positive to marijuana use. This value structure has been characterized in the literature as an attitude of tolerance toward deviance, and tolerance toward marijuana use (Jessor et al., 1973; Kandel, 1980). Positive attitude toward the act contains a belief component regarding expected outcomes. Bearden, Woodside, \& Jones (1979) conclude that: "...individuals with plans to use marijuana appear to believe that the use of the drug leads to a pleasant experience while not leading either to personal physical danage or legal ramifications" (p. 750).

Imagined expectations of the drugs' intrinsic effects appear to be a behavior determinant. Once consumed, properties of the drug then serve as nonsocial reinforcers to maintain or discontinue using the drug (Kandel, 1980). Expectations of the drugs' effects, before and after initiation may well follow Ray's (1972) analysis:

At the most fundamental level, all drugs used recreationally on a regular basis directly or indirectly either increase pleasure or decrease discomfort. (p. 271)

Increasing Pleasure and Decreasing Pain

Schlegel \& Norris (1980) determined that beliefs that marijuana use is pleasurable and fun was most predictive of marijuana use with 
high schnol and college students. An earlier survey by LaDriere, Odell, \& Pesys (1975) found "...100\% of the high school [marijuana] users...rated the pleasure of the high as one (if not the only) reason for use" (p. 303).

Alcohol, too, is expected to enhance pleasure. Yancy, Nader, \& Burnham (1972) studied adolescent perceptions of reasons youth use drugs. "More than half of the students (55.4\%) stated that youth begin to use alcohol becasue it was pleasurable" (p. 741). Thus, it appears a belief that drug use is pleasurable may be predictive of its use, and the ability of the drug to deliver a pleasurable experience solidifies the belief structure, while reinforcing continued usage. Belief is enhanced by experience, and the initiate then is able to confirm and communicate this belief to others.

Once learned, expectation of outcomes also can shape behavioral responses causing a placebo effect as in the following study reported by the National Institute on Alcohol Abuse and Alcoholism (1978):

Subjects' expectations about alcohol are highly relevant: those who believed they had drunk alcohol acted more aggresively than those who thought they had consurned a nonalcoholic beverage, regardless of the actual contents of the drinks. (p. 54)

In this situation, the individuals' exercised cognitive control of their behavior based on personal expectations of the drugs effect.

Attitude toward the act, and expectation of outcomes of drug consumption continually interact with, and respond to individual perceptions of internal and external events. We may conceptualize the substance user as one who has "numerous needs that are percieved as being satisfied to some degree by the drug..." (Gorsuch \& Butler, 1976, p. 132). While the individuals' perceived need and behavioral response 
may range from curious experimentation to compulsive consumption, certain internal personal correlates appear to separate experimenters from potential drug abusers. Goodman (1972) identified two dominant predependency motives, psychic pain and inability to cope. While the author proposes that inability to cope is the predominant predependency motive, this reviewer suggests that it may well be some degree of psychic pain, with which the individual is unable to cope that triggers abusive drug consumption. Scherer et al., (1972) note that the individual who is a chronic hard drug user "...will be lacking a realistic solution to his problems" (p. 120). Thus, it seems likely that psychic pain and inability to cope both will be evident in those who become chemically dependent. Experiencing a decrease in discomfort is an expected outcome of drug consumption. Alcohol often is perceived to be a means of relieving tension, anxiety, and general depression. Its efficacy is equivocal however. McClelland (1971) states that five or six drinks were necessary to significantly reduce the anxiety thoughts of college male subjects. On the other hand, williams, (1966) found that at moderate levels of consumption, adolescent problem drinkers experienced some decrease in anxiety, however, severe intoxication did not seem to relieve these symptoms, and of ten made them worse. If severe intoxication does not relieve male adolescents' psychic pain, then motivation for progressive intoxication beyond a level of initial tension and depression relief cannot be explained as the direct effect of the drug in decreasing this pain. Other possible motives, including low self-esteem and male gender role conflicts will be discussed later. Research by Gorsuch \& Butler (1976) suggests the cognitive state 
of boredom is related to mental anguish and may dispose an individual to drug experimentation and use. Internal sensation seeking individuals appear to require greater stimulation than is available from their environment. Drug consumption may relieve the distress caused by a lack of adequate external stimulation (pp. 129-130).

Because marijuana causes the person to focus on the present (Melges et al., 1971), while decreasing sensitivity to external events, responsiveness to internal events appears to be enhanced during marijuana intoxication (Tinklenberg et al., 1972). An investigation by Eisenman, Grossman, and Goldstein, (1980) of the personality traits associated with marijuana use yielded the following:

The only dimension of novelty seeking sianificantly related to frequency of marijuana use was internal sensation seeking. As frequency of marijuana use increased, internal sensation seeking increased... After 2 years of marijuana use, desire for novelty decreases significantly... [that is] there is a significant drop in expressed boredom, or conversely, increased satisfaction with the environment. At the same time, however, there is no decrease in adventuresomeness or any form of novelty seeking. It appears that traits of adventuresomeness or novelty seeking are motivated by something other than boredom, at least as far as the measures we used are concerned. (pp. 1016,1018 )

Thus long term and frequent use of marijuana may not be motivated by boredom. Victor, Grossman, \& Eisenman (1973) noted that "multiple drug users...scored much higher than the marijuana-only group on internal sensation novelty seeking..." (p. 84). The research suggests that frequent and long term marijuana users, and the multipe drug users want and/or need greater degrees of internal sensation stimulation.

Low Self-Esteem

In his longitudinal study of junior high school students Kaplan 
(1977), tested a general theory of deviant behavior. The theory postulates a "...self-esteem motive, according to which a person engages in deviant activites in order to restore a sense of self previously damaged by self-devaluing experiences in his/her membership group" (cited in Kandel, 1980). Kaplan's research supports the hypothesis that negative self-feelings are predictive of deviant behavior including drug use. Kandel (1980) summarizes Kaplan's findings:

...high initial levels of self-rejection and lowering in self esteem over time predicted subsequent involvement in one or more of 22 deviant behaviors, among them the use of alcohol, marijuana, and narcotics....initiation of a deviant activity was followed by a reduction in negative self-image... (pp. 255-256)

A review of the literature on personality correlates of adolescent problem drinkers identified them to be characteristically "...lacking in personal controls, as evidenced by relatively high aggressiveness and impulsiveness...relatively low self-esteem, high anxiety, depression, and general lack of success in the attaiment of life goals" (Braucht, et al., 1973). Drinking behavior also increases during stressful situations which were perceived to be threatening to one's self-esteem (NIAAA, 1978).

Low self-esteem as well as low expectation of achievement may be self-produced conditions of distress. When one's behavior or accomplishments bring a sense of self-criticism or failure, defensive reactions such as excessive drug consumption, which avert or lessen discomfort, are reinforced (Bandura, 1977, p. 141). Alcohol is seen as especially functional in that it anesthetises any psychic pain. It allows the person to engage in disinhibited behavior which can be perceived as socially acceptable because it is provoked by alcohol, at the same time relieving 
the individual of responsibility for such behavior (Arnao, 1976). Low Value On, and Expectation of Achievement

As discussed in Chapter three, low valuing of achievement is correlated with initiation to drug use. The learned perception of oneself as not being able to perform adequately may also contribute to lower self-esteem. However, not all marijuana users are academically deficient. In a study of high school students, Green, Blake, Carboy, \& Zerhausen, (1971) were able to distinguish two groups; high performance and low performance marijuana users. "The high-performance user was found to be intelligent, alert, confident, and sensitive, while the lowperformance user was depicted as being shy, cynical, unstable, and less able to handle abstract thinking" (Braucht et al., 1973, p. 100). Thus, the stereotype of the marijuana user as an underachiever does not necessarily hold. The low expectation of achievement correlate, as with others, may be relevant only when combined with other personal and environmental factors.

High Rebelliousness

The personality characteristic of rebellious behavior often is cited as an antecedent correlate of drug use (Hogan, Mankin, Conway \& Fox, 1970; Kandel, 1980). Huba, Wingard, \& Bentler's (1980) longitudinal data attempts to explain why this association has occurred, and disputes the trait-attribution notion:

Within this context, the empirical finding that rebelliousness tends to dispose an individual to drug use... may be theoretically interpreted as follows: rebellious tendencies predispose an individual to belong to a counter nonmative subculture, but only some of these subcultures 
represent support systems for drug use of various forms. (p. 277)

The authors conclude that indications of small degrees of deviant behavior such as rebelliousness do not significantly increase prediction of adolesent drug use.

High Adventuresomeness and Risk Taking

Curiosity is given as the primary reason for ever trying marijuana by over $60 \%$ of adolescents surveyed (Eisterhold, Murphy, \& Beneke, 1979; Yancy et al., 1972). Clearly, adolescents are cognizant of legal and social sanctions against their use of licit and illicit drugs. Choosing to experiment with chemical substances is both risky and adventurous. Once curiosity is satisfied, and the novelty of adventure wanes, does risk taking, as a personal behavior determinant change? The analysis of Sadava \& Forsyth (1977) revealed that large positive changes in risk values were found to predict high frequency of marijuana use. Among single criterion predictive of multiple drug experimentation were personal factors of "...high values for independence, peer conformity, and risk; high social alienation, tolerance of deviance, and drug use; [and] low delay of gratification, time perspective, [and] expectancies for interpersonal trust..." (p. 219).

Low Inpulse Control / Low Delay of Gratification

Graham \& Cross (1975) found adolescents who do become substance users to be disdainful of rules and authority, favoring "...personal experience and happiness, doing what feels good, and individual choice as criteria for determining personal behavior and values" (p. 104). 
These subjective standards for decision-making suggest a low degree of impulse control or, conversely, a high valuing of immediate gratification. Low impulse control and low delay of gratification are correlated with chemical substance use and abuse in much of the literature (Green et al., 1971; Hogan et al., 1970; Victor et al., 1973). Research by Sadava and Forsyth (1977) found high risk values, low delay of gratification, and lower personal locus of control to suggest reduced personal control as frequency of marijuana use increased (p. 224).

As with other behavioral correlates, impulsivity does not always lead to drug involvement. Impulsive behavior may be a response to other internal personal factors which are expressed in this manner. Once discovered however, the ability of drugs to provide almost immediate sensate change serves to reinforce continued, possibly uncontrolled drug use/abuse in impulsive persons.

\section{High Independence}

Reduced personal control seems antithetical to the value adolescents place on perceiving themselves as being in control and projecting independent behavior. Tudor, Petersen, \& Elifson, (1980) detemined that adolescent drug users were highly independent from their parents but not so independent from their peers. This research "...did not support the hypothesis that the more independent the adolescent is from peers the less the likelihood of drug use" (p. 793). Jessor, Jessor, and Finney (1973) found that junior high school marijuana users "...value achievement less and independence more than nonusers and also also show a greater discrepency between the two values, in the direction of independence, 
than do nonusers" (p. 6). This value orientation was evident in the high school sample as well, and is linked to marijuana use by conceiving marijuana consumption as a behavior which can "...serve to repudiate authority, to lay a claim on a more mature status, or to cope with the frustrations of assigned immaturity" (p. 13). Similarly, Carman (1973) suggests that "...drug use may be more directly related to preferences for independence, freedom from interference by others, and the opportunity for autonomous decision making" (p. 737).

In this context, all drug use may be perceived by adolescents (who are subject to much regulation on the basis on their age-status) as a means of expressing independence as well as protesting or rejecting social and legal sanctions.

Low Interpersonal Trust

Sadava \& Forsyth (1977) found that an individual's perception of a drug as having high positive functions and low negative functions were most predictive of drug use (p. 224). High frequency marijuana use was predicted by "relatively low interpersonal trust scores, specifically in the peer trust subscale..." (p. 224). A picture emerges of an individual who may be characterized as a loner.

In combination with changes toward greater social alienation, and high values for independence with regard to both family and peers, the pattern suggests personal isolation associated with high frequency, while the positive loading on positive instrumental functions suggests something intentional in this isolation. (Sadava \& Forsyth, 1977, p. 224)

Using data from analyses of the Minnesota Multiphasic Personal ity Inventory (MMPI) responses, McAree, Steffenhagen, and Zheutlin (1969) found marijuana only users to be comparable to the control group. 
However, multiple drug users ranked high on the schizophrenia scale which represents "...withdrawal, poor interpersonal relationships, aloofness and the inability to express emotions..." (Braucht et al., 1973, p. 101).

The idea of intentional isolation raises the question of motives for self-isolation. On one hand one may have internalized a perception of social situations as being unrewarding and/or hostile and threatening, causing a response of withdrawal inward. In this instance drug use would become highly functional and facilitative, and concentration on here-and-now, internal life events would allow one to disassociate from the environment without irmediate perceived emptyness.

on the other hand, when the adolescent is insecure or ambivalent with interpersonal peer relationships, the tendency to withdraw may be attenuated by the perception of drug use as a means to achieve a peer group inclusion. Graham \& Cross (1975) identified a "...fear of isolation or being left out..." in drug users, while scherer et al., (1972) observed that chronic drug users have "...an abnormal desire to be looked upon favorably" (p. 120).

Adolescents who have little sense of warmth and 'belongingness' with their parents, and who are insecure in peer relationships may also perceive a lack of caring from people in their school envirorments. As Graham \& Cross (1975) have stated "...the drug users could easily conceive that no one cared about what they did...such an attitude would have wide implications for their behavior" (p. 104).

GENDER ROLE CORRELATES

Differential socialization practices influence adolescent gender 
role development. Individual perception of gender behavior expectations are shaped by reinforcement and modeling during infancy, and continue to be defined throughout adolescence and adulthood. Perceived sociocultural expectations projected by family members, peers, and media personalities interact with personal conceptions of self in relation to perceived models, and salient rewards or punishments for behavior. The emerging gender role identity will influence subsequent behavior and personal requirements for self-approval.

O'Neil (1981) defines the concepts of gender role conflict and strain as follows:

Gender role conflict is a psychological state in which gender roles have negative consequences or impact on the person or others. The ultimate outcome of this conflict is the restriction of the person's ability to actualize their human potential or the restriction of someone else's potential... Gender role strain is excessive mental or physical tension caused by gender role conflict and the effects of masculine, feminine, or androgynous roles. (p. 203)

Rigid gender role socialization is likely to create gender role conflict and strain.

Male

Male adolescents are more likely than females to use and abuse all categories of licit and illicit drugs (Kandel, 1980). While the percentage of male and female adolescents who ever drink or use marijuana does not differ significantly, almost twice as many male adolescents are problem drinkers, and twice as many are daily marijuana users, compared to female adolescent problem drinkers and daily marijuana users (Johnston, Bachman, \& O'Malley 1979b; NIAAA, 1978).

Mary Cover Jones (1968), using longitudinal data gathered during 
junior high school, senior high school, and adulthood, outlined a number of personality characteristics which differentiated male problem drinkers from male non-problem drinkers at these three stages of their lifespan. By identifying personality characteristics prior to onset of alcohol use, and tracking personality correlates and alcohol use patterns, Jones identified personality features early in adolescence which appeared to predispose males to subsequent problem drinking. Male pre-problem drinkers differed from male pre-normal drinkers mainly in the degree to which specific personality traits were present. Those traits which were evident at the junior high level and maintained through adulthood included, uncontrolled impulsive and extroversive behavior (such as hostility, assertiveness, and rebelliousness), sensitivity to criticism, over-emphasis on masculinity and inability to maintain adequate interpersonal relationships (pp. 8-10).

While assertive and impulsive behavior which projects a masculine image may enhance same-sex interrelationships during the latency period (Jones, 1965), these same characteristics may cause conflicts during adolescent male-female group formation. The high value this sample of male pre-problem drinkers placed on masculine behavior indicates an underlying socialization process which models and rewards masculine behavior while punishing non-masculine behavior.

In his excellent discussion of male gender role conflict and strain O'Neil (1981) suggests: "when a man fears his feminine side he really fears that others will see him as stereotypically and negatively feminine" (p. 206). Fear of femininity in self, or confused sexual identiy may cause the male adolescent to overreact and compensate by exhibiting such behavior as toughness, aggressiveness and excessive 
alcohol consumption (McClelland, 1971). Parker (1969) found that male college students with strong alcohol dispositions wanted to be perceived as being masculine, however they were unable to identify personally with masculine traits. Alcohol consumption may be perceived as useful for maintaining a masculine facade and for assuaging internal distress caused by lack of integration and acceptance of the traits attributed to the "feminine" self.

Issues of control, power, and dominance also surface when considering male gender role conformity and alcohol use.

The socialized masculine mystigue suggests that control, power, and competition are essential to proving one's masculinity. Control and power are vital to a man's positive self-image, and competition is the vehicle to obtaining both. (O'Neil, 1981, p. 207)

In his extensive cross cultural research of psychosocial correlates of male drinking behavior McClelland (1971), concluded that the excessive male drinker "...is the man with an excessive need for personal power who has chosen drinking as the way to accentuate his feelings of power" (p. 78). McClelland's research reveals the cognition and affect underlying male power thoughts at different levels of alcohol intoxication. Two kinds of power thoughts emerge. One is an altruistic power, of exercising influence on behalf of others. This type of power thought predominates after one to three drinks. The second kind of power thought involves aggressive dominance over others. With heavier drinking, fear anxiety thoughts and altruistic thoughts decrease, and aggressive dominance thoughts prevail. It is possible that increased positive feelings of power, and power concerns are either enhanced or expressed through the act of drinking (McClelland, 1971).

Because men fear other men will devalue them for less than maximum 
masculine behavior, control, power, and interpersonal competition are used to establish personal superiority in group situations (O'Neil, 1981). That drinking exacerbates these conditions is evident in research reported by NIAAA (1978): "When male social drinkers drank in a competitive group situation, inter-personal aggression increased significantly" (p. 54). It further asserted that "In contrast, when male female couples interacted in an unstructured way, neither aggression nor hostility increased systematically in the drinking subjects" (p. 54).

It appears that the men's perception of required behavior changed with the environmental change. This reviewer suggests that the introduction of females into the group provided opportunity for covert sexist behavior, thus relieving the need for overt aggressive demonstrations of dominance.

Clearly, adolescent males experience strain and conflict as they mature. External social and cultural influences throughout their lives continue to influence and encourage them to aspire toward a stereotypical male image. Denial and repression of facets of the self may occur while trying to fit into the valued masculine model. Subsequent incongruity may become manifest in some form of psychological or physical distress. Means of coping with the pain, and avoidance of the stresses of becoming the culturally acceptable male include alcohol and drug consumption and abuse.

Female

That female adolescent chemical substance abuse occurs less frequently than it does for males may be a result of differential gender role socialization and cultural expectations. Female children tradi- 
tionally are protected by the family, socialized to adhere to established standards of feminine behavior (passive, submissive, conforming), and are not rewarded for characteristically male behavior such as assertiveness and rebelliousness. More women than men have their first alcohol experience in the context of the family setting (Jones, 1971). In situations where the family models responsible alcohol use, female adolescents are likely to learn socially appropriate alcohol consuming behavior (Mercer, Hundleby, \& Carpenter, 1978). In homes where there is an alcoholic parent, Jones (1971) reports that female adolescents are more likely to react to the alcoholism (especially a father's alcoholism) by becoming light drinkers or abstainers.

In her longitudinal study of a female sample in junior high school, senior high school, and adulthood, Jones (1971) determined that female problem drinkers, in contrast to male problem drinkers, were substantially different from normal drinkers of their same sex. Surprisingly, the female problem drinkers and female abstainers had several similar personality characteristics which emerged early and remained through their adult years. The pattern suggests that both groups may have inadequate coping skills (p. 63). Jones (1971) outlines the personality correlates indicative of female pre-problem drinkers and abstainers:

They are self-defeating, vulnerable, pessimistic, withdrawn; they feel guilty, somatize, and project feelings. They are less productive, incisive, independent, and selfsatisfied with fewer interests and with lower aspiration levels than nomal drinkers. (p. 63)

However, certain personality traits differentiate the female problem drinkers from abstainers. While the abstainers were found to remain conventional and emotionally controlled, the problem drinkers 
were judged to be "...submissive as youngsters, [and] rebellious as adults" (Jones, 1971, p. 64).

Female pre-problem drinkers also were found to share some cammon personality charactistics with male pre-problem drinkers. Notably they were sensitive to criticism, hostile, unpredictable, and impulsive. The sum of their personal behavior indicates that they would be likely to have difficulty maintaining interpersonal relationships (Jones, 1971). Those attributes which distinguished female pre-problem drinkers fram their male counterparts, include tendencies toward depression, self-negation, and distrust (p. 68).

Drinking excessively may be a way the female can "mitigate feelings of despondency and inadequacy" (Jones, 1971, p. 63). Women who became problem drinkers often suffer from deep emotional pain and may be subject to social isolation. Unlike men whose "machismo" image often is enhanced by alcohol consumption and abuse, excessive drinking by women is subject to social criticism and personal censure. Consequently women are more likely to conceal their drinking patterns. Because socialized gender role stereotypes are pervasive, concentrating on personality traits predictive of male and female problem drinking may be extremely beneficial in designing intervention and prevention programs. Rigid gender role definitions restrict selfexpression for both males and females. Perceived environmental requirements, cambined with personal expectation and self-evaluation may set up a condition which causes severe internal pain for adolescents, and may, in part, explain their desire to find solace and canfort through drugs. The impact differential gender socialization has on increasing pressure on adolescents to use and abuse chemical substances 
should alert educators, counselors and the general public. Ameliorating rigid expectations for male and female gender role behavior may help prevent future adolescent chemical substance abuse.

\section{SUMMARY}

While modeling effects of parents, peers and others (such as teachers and media idols) contribute to the adolescent's development of attitudes toward drug use, the individuals' perceptions of and experiences with chemical substances may be more important in developing attitudes and behavior patterns (Gorsuch \& Butler, 1976).

Initial use of any drug appears to be dependent upon an attitude favorable toward use, and a perception of the drug as being pleasurable. Use patterns tend to be established on the basis of conscious or unconscious need, and the perceived ability of the drug to fill the need (reinforcement).

A parallel continum illustrates how levels of use develop relative to personal determinants:

\begin{tabular}{cccc} 
INITIATION & SOCIAL/RECREATIONAL & PROBLEM/ABUSIVE & \multicolumn{1}{c}{ CHRONIC } \\
\hline CURIOSITY & INCREASE PLFASURE & DECREASE PAIN: & DEPENDENCE: \\
& & UNABLE TO COPE & RELINQUISH \\
& & & SFLF-CONTROL
\end{tabular}

The individual's placement within this continuum in part is dependent upon the degree to which internal personal correlates are operative. Some personal correlates may span all levels of involvement, but be more intense in one person over another. These include internal sensation requirements, risk taking, value of independence, and impulse control. An initiate who becomes a social or recreational user may perceive the drug to reduce anxiety, enhance feelings of peer efficacy, 
and/or diminish sensations associated with gender role conflicts and strain. Heavier users may experience these same effects and also possess additional personal correlates of low expectations for achievement, low self-esteem, low peer-trust and intense psychic pain. Inability to cope, combined with increasing druq dependence growing out of problem use may lead to chronic use, withdrawal from social responsibility and relinquishment of personal control over the self.

Attributing drug use/abuse to either environmental support systems (ie. parents, peers) or personal characteristics (i.e. genetic predispositon or addictive personality) does not hold up to empirical research (Sadava \& Forsyth, 1977). Drug using behavior is precipitated by a reciprocal interaction process involving both internal personal factors, and environmental forces. The complex and unique mixture of internal and external variables determines the individual's level of involvement (or noninvolvement) with licit and illicit drugs. "Although the research literature can identify drug users/abusers with given personal attributes, [and from given environmental systems] one cannot predict or infer that these attributes lead inevitably to drug problems..." (Sadava \& Forsyth, 1977, p. 237).

Environmental determinants most salient to predicting drug use or abuse include parents and peers. Role modeling of drug use/abuse by by significant others, low affinity in parent-child relationships, and either high need for peer support or low peer trust, appear to be predictive of increased levels of adolescent drug involvement.

Personal determinants most salient to drug use/abuse precipitation include psychic pain, inability to cope and a perception of the drug usage as fulfilling positive functions (increased pleasure, decreased 
pain). More intense feelings of need and greater perception of drugs as helpful produce increased drug involvement. Personal and social ramifications of drug abuse and dependence necessitiates a continuing effort on the part of helping professionals to understand predispositional contingency sets active among adolescent drug users. Intervention, prevention, and rehabilitation procedures must recognize and address the multiple intertwining systems operative in drug using and abusing behavior. Thus a group counseling program is proposed as an effective intervention model which is sensitive to the intellectual and psychological developmental needs of adolescents. 
CHAPTER V

\section{A MODEL FOR GROUP INIERVENTION}

\section{INIRODUCTION}

So long as drugs exist, adolescent drug experimentation and socialrecreational use of these substances is likely to occur. Efforts aimed at eradicating all chemical substance use would appear to be frustrating and futile. Therefore, a more realistic program goal may be drug abuse prevention and intervention. Moreover, if the drug abuse prevention program also fosters prevention of drug use, then it would exceed expectations of its purposes.

Because individual behavior is influenced by numerous environmental systems, a prevention and intervention program which includes environmental elements seems likely to have a greater dhance of effecting desirable change over time. The proposed model for group intervention addresses the issue of enviromental forces acting upon the individual throughout the ten session program. However, no one person nor one institution can be expected to change adolescent drug using attitudes and behaviors. Schools which have tried operating programs without coordinating involvement of individuals and agencies across the community have experienced little success (Aubrey, 1973). Therefore involving other community institutions and agencies as well as parents and the student population in the change process is highly desirable. Community and school druq 
prevention programs which work together may be more likely to identify children from drug dependent families, and develop support groups for these young children (Black, 1979). An example of a successful model for activating public and parent awareness, integrating community programs (law enforcenent and drug rehabilitation) with school administrative policies and procedures is operating in the Vancouver School District, in Vancouver, Washington.

Schools have a unique opportunity to open their procedural policies to greater student involvement. Due to status laws, adolescents are in an uncomfortable state of being told to respect and uphold the principles of democracy without actually participating in the democratic process. In his fine sumnation of a school program aimed at removing drug usage from the school campus, wright (1979) outlines a set of principles and policies which appear to be applicable to a number of school environments. He suggests "...students are in a much better position than principals and teachers to transform schools in desirable ways" (p. 48). By providing students with channels to become involved in the decision making procedures, students came to perceive themselves as part of the power structure of the school. Students recognized a need to get drug abuse off campus and developed the program they wanted to enact toward that goal. This meaningful participation of adolescents fostered trust and personal investment in the program outcomes. With such a vast resource of energy and potential for positive change-making available, schools may well be advised to examine their own 'power motives' and reassess policies and procedures in this light.

Because drug education programs whose primary purposes are to dispense information about drugs and their psychological and physiological 
effects appear to be of questionable value (Horan, 1974; Stuart, 1974; Vogt, 1977). The proposed group intervention model emphasizes more indirect methods. While outcomes may be more difficult to measure (Horan, 1974), concentrating on the internal, affective forces operative in the adolescents life, as well as external influences conducive to potential chemical substance abuse, is justified by the literature herein reviewed. Thus, sessions one through seven of the proposed program integrate recognizing and building positive personal coping skills, a need identified in Chapter IV. Positive interrelationship development, found to be an integral issue surrounding adolescent drug abuse (Chapter III and IV), is intrinsic to the group method and is emphasized in sessions four, five and six. Enhancing positive selfconcept, a need identified in Chapter IV, is developed during sessions seven and eight. Adolescent attitude toward the act and expectation of outcomes of drug abuse are addressed by integrating decision making with personal values and lifestyle choices throughout the model and especially in session nine.

Attitudes toward drug use may prove highly resistant or reactive to change. Those adolescents who already resist socialization into culturally traditional roles, while endorsing nonconventional values and behavior, may be expected to resist traditional values oriented treatment (Wingard, Huba, \& Bentler, 1979). Certain belief structures surrounding drug use appear to be more reactive than others. Schlegel and Norris (1980) found that beliefs associating drug use with pleasure are especially reactive. Thus, while attempting to dispose adolescents to hold less favorable attitudes toward drug use, persuasion which portrays the activity as unpleasant may increase positive beliefs and 
strenathen behavioral intention. It appears that appealing to other components in the belief structure, especially perceptions of personal control of actions while intoxicated, may reduce intentions and behavior regarding marijuana smoking (Schlegel \& Norris, 1980). Therefore, sessions four and five of the proposed group intervention program stress accepting responsibility for personal behavior choices.

Carney's 1972 longitudinal examination of values clarification programs in public schools indicates that students who participated in these classes had less initial use of alcohol and marijuana than those who did not. As Aubrey (1973) has stated:

The decision-making process...to abuse or not abuse drugs, is inexorably interwoven with the entire fabric of the individual's value system. As a consequence all drug programs must begin and end with recognition of this reality. (p. 5)

Regardless of the level of drug involvement and nature of intervention, peer saliency is generally high among adolescents. Where family affinity is low, adolescent confidence in other adult authority figures decreases. Consequently these youngsters are likely to turn to drug using friends or former drug using peers for help (Babst et al., 1978). With this principle in mind, an ongoing drug use/abuse intervention and prevention program should train and utilize adolescent peer counselors for both individual and group counseling purposes (Bell, 1978) .

In addition to establishing an attitude of acceptance and caring about all adolescents, both the school and the guidance department can best serve students by fostering a climate of trust and acceptance toward drug experimenting youth, without condoning the behavior (Aubrey, 1973). Adolescents need to feel the presence of non-judgmental attitudes 
of caring and accepting them as people. It is posited that the school guidance department can make a commitment to assist adolescents who are engaging in (or contemplating) licit or illicit drug experimentation by establishing a group counseling program. The next section proposes a model for a group counseling program within the public school setting for the prevention of drug abuse.

\section{A PROGRAM FOR GROUP COUNSELING}

Group counseling, with adequately trained facilitators, can provide a secure and comfortable environment conducive to self-exploration and change. By providing peer as well as adult role models, feedback, and support systems, each individual's strengths may be enhanced, and weaknesses diminished.

The proposed program will help counselors facilitate building those skills which have been identified as being helpful to adolescents who are at the point of making choices regarding initiation of chemical substance use and abuse (Aubrey, 1973; Jessor et al., 1973; Jones, 1968; Jones, 1971; Kandel, 1980). The program is designed to help adolescents identify and modify personal coping behaviors; to learn new communication and interpersonal relationships skills; to recognize and build upon personal strengths; to take responsibility for personal decisions, choices and behavior; and to integrate values, lifestyles, and life goals with behavior choice and decision-making. The program structure, activities, and process are sequential, educational, and experiential in nature.

Facilitators for this group must be knowledgeable about the topic of chemical substance use and abuse, have a firm understanding of their 
values and attitudes, and demonstrate congruity between their language and patterns of behavior. Adolescents are very sophisticated and perceptive. Uninformed and inadequately trained group leaders may do more harm than good.

To ensure a productive group experience, attention is focused on the selection of group members; duration, frequency and length of sessions; the setting; and, group leadership.

Selection of Group Members

Participants will be selected by the group facilitators through careful screening of students who have been identified through informal outreach efforts, referred by other school sources such as teachers, counselors, administrators, or other students, referred by parents, and self-referred. Since the targets of the program are individuals on the verge of initiating drug activity, individuals who are ascertained to be chemically dependent will be referred to rehabilitation therapy.

Prospective members are informed that the group experience is designed to help participants learn more about themselves and to develop and refine communicating, coping, and decision making skills. While drugs will be an integral topic of discussion, the primary purpose of the group is more than the dissemination of drug information and sharing of drug-related experiences. The group will include only those students who have a commitment to conscientious, introspective participation. Facilitators will adhere to the school policies for securing parental permission.

A group of six to eight male and female adolescents will encourage diversity of experience and insure intimacy while providing for extensive 
individual participation.

Duration, Frequency, and Length of Sessions

The program consists of ten sessions, one per week, each lasting about 90 minutes. The first and last sessions are introductory and summarizing in nature. Follow-up sessions will be determined from student and facilitator feedback. During the course of each session, time and consideration will be given to individual and group concerns. The program is intended to be flexible so that sessions may be modified and expanded by facilitators to fit the needs of the group members. It is not likely that all members will have the same levels of need or self-awareness. Therefore, facilitators may want to arrange concurrent individual counseling sessions.

\section{$\underline{\text { Setting }}$}

The environmental setting should be private, comfortable, and aesthetically pleasing. An ideal sized room would accomodate four or five dyads which do not physically or auditorily interfere with one another. Furniture should be moveable to adapt to group activities.

\section{Group Leadership}

Knowledgeable, professionally trained and self-confident facilitators are essential. Use of both adults and students as peer co-facilitators for each activity are recommended in order to build trust, widen perspectives, and provide immediately available role models. The subject matter involved requires that facilitators be informed about drug using behavior, and have undergone intense self-examination of their own 
behavior, personal biases, and attitudes toward drug use and abuse. Facilitators must be able to draw upon their own knowledge and experiences to enhance the group experience without proselytizing or preaching about chemical substance use and abuse. Knowledgeable facilitators will be able to supply appropriate printed information and make appropriate referrals.

\section{SESSION I: DEVELOPING AWARENESS OF GROUP FUNCTIONS AND DEFINING RESPONSIBLE CHEMICAL SUBSTANCE USE}

Purpose: To express structure, rules, and processes of the group; to become acquainted with group members, their goals and expectations; and to define responsible chemical substance use.

Materials needed: Paper, pen or pencils, chalkboard and chalk, handouts; "Feedback" (Appendix A), "Definition of Self-Disclosure" (Appendix B), "Identifying Environmental Pressures" (Appendix C).

\section{Activities:}

1. Large Group Activity: Introduction of group. Instructions to facilitators: a) Briefly introduce the co-facilitators, group members; b) Discuss the rules of group (membership, confidentiality, attendance, promptness, participation). c) Using "Feedback" and "Self-Disclosure" handouts, discuss rules for constructive feedback, definition of selfdisclosure, and the concept of concensus. Time: 20 to 25 minutes. 2. Large Group Activity: Getting acquainted. Instructions to facilitator: a) Have group members walk around and nonverbally greet one another (handshake, smile, nod). b) After a few minutes have them pick a person they would like to know better to talk with. c) Instruct them to sit down together and interview each other for five minutes. 
d) Then have pairs introduce each other by sharing information about the other person to the group, telling four or five important things about their partner. e) The person who was introduced will add one more important piece of information and describe his or her goals and expectations for the group experience. Time: 35 to 40 minutes. 3. Small Group Discussion: Defining responsible substance use. Instructions to facilitators: a) Randomly divide the group in half with one facilitator per group. b) Sit in two separate circles and give both groups the following assignment:

1. As a group define: a) responsible chemical substance use, and,

b) chemical substance abuse. Concentrate on alcohol and marijuana use. Be specific.

2. Choose a recorder and a spokesperson to report your group's definition to the large group.

3. You must reach concensus within your group (everyone agrees at least a little with the definition).

4. Complete the assignment within ten minutes.

Facilitators will note the roles assumed by various group members, and encourage participation by all members, and assist groups in moving toward concensus. Time: 15 to 20 minutes.

4. Large Group Discussion: Defining responsible chemical substance use. Instructions to facilitators: a) Return to total group and have spokespersons report their groups definition. b) Facilitator will write each definition on the chalkboard. c) The full group must then negotiate and arrive at concensus about their definition. d) Write the final definitions on the chalkboard and instruct group members to make a copy for themselves before leaving. Time: 10 minutes. 
5. Allow the group members to reflect and make comments about their observations, the definitions, and the experience. Time: 5 to 10 minutes. Handouts: Facilitators may hand out selected material from Do It Now Publications (Worden \& Rosellini, 1981), or from the National Institute of Alcohol Abuse and Alcoholism and the National Institute on Drug Abuse, for group members to use as comparison with their group definitions. Homework: Instructions to facilitators: Group members will keep a loose leaf journal in which homework assignments, handouts, baseline data and behavior change progress will be recorded. Experiences and insights gained during the group sessions also may be included. Information from journal recording will be used in subsequent group sessions. Confidentiality concerns should be addressed by instructing the group members to use colors, letters, or numbers rather than names when identifying specific people. Instructions to students: During the next week identify environmental sources exerting pressure upon you to use or abuse chemical substances and record how you respond to the pressure. Using the "Identifying Environmental Pressures" worksheet, determine who, what, where, when and how the pressure occurs, and your response.

SESSION II: IDENTIFYING COPING BEHAVIORS

Purpose: To develop awareness of feelings and thoughts, am how outward behavior flows from inner perceptions; to recognize some personal coping behaviors.

Materials needed: Pen or pencils, chalkboard and chalk, exercise sheets: "Good Feelings" (Appendix D), "Bad Feelings" (Appendix E), "Behavior Change Planning Guide" (Appendix F). 


\section{Activities:}

1. Large Group Activity: Identifying feelings. Instructions to facilitators: a) Give each group member a "Good Feelings" and a "Bad Feelings" work sheet, and pen or pencil. b) on the "Good Feelings" sheet, instruct students to list at least five different "good" or positive feelings they have almost every day. c) On the other, list at least five "bad" or uncomfortable/negative feelings they have almost every day. d) When students are finished, instruct them to think about each feeling they listed and next to it write a short, specific description of what they do when they have that feeling. Making "I feel" sentences may help in this process, for example: When I feel nervous, I usually handle this by laughing a lot. Time: 10 to 15 minutes.

2. Small Group Activity: Identifying sources of feelings. Instructions to facilitators: a) Have group members pair into dyads and share their lists with one another. b) Using the left hand column of their exercise sheets, instruct them to help each other identify whether each feeling is something that comes from within themselves, or is being influenced and modeled by someone or something outside of themselves. Time: 10 minutes. 3. Large Group Activity: Sharing feelings. Instructions to facilitators: a) Return to large group and instruct inembers to choose one positive and one negative feeling and share the feeling and its consequent behavior with the group. b) Facilitators will model by recording a feeling and behavior on the chalkboard. c) When all inembers have had their turn you may wish to go around a second time for those who have other feelings and behaviors they want to add. d) Facilitators will use the exercise to point out: Commonality or disparity of feelings to build understanding of self in relation to others; how thoughts and 
feelings lead to actions; how our actions show our ways of coping (including drug use and abuse); and, what we tell ourselves are the reasons for our feelings and our behaviors. Time: 35 to 40 minutes. 4. Large Group Discussion: Homework assignment. Instructions to facilitators: a) Using the homework assignment from the previous session ask each group member to identify one particular environmental pressure to use or abuse chemical substances from their own experience (substitution of color, number, letter is preferred when specific people are involved). b) Facilitators will model by disclosing environmental pressure they experience. Go around the circle until each member has shared his or her experience with the group. Illustrate how outside forces affect our internal thoughts and feelings as well as our consequent behaviors. c) Brainstorm alternative coping methods. Time: 35 to 40 minutes.

Homework: Instructions to students: Monitor your own and observe other people's coping methods during the next week. Devise a preliminary plan to deal with the pressure you experience to use or abuse chemical substances. Using the "Behavior Change Planning Guide" determine what you could do before, during, or after the pressure situation to help yourself. What rewards could you give yourself if you achieved your goal? Bring these preliminary ideas to the next group session.

SESSION III: USING REIAXATION AND GUIDED FANTASY AS COPING METHODS

Purpose: To follow-up on observatons about coping methods; to provide relaxation training through guided fantasy; to establish a specific behavior change goal.

Materials needed: Comfortable chairs, or pillows in a carpeted room; 
quiet, warm, easily darkened room. Activities:

1. Small Group Activity: Behavior change goals. Instructions to facilitators: a) Divide into two groups, one facilitator each. b) Facilitators will model and then ask each group member to use their homework assignment to tell the group about one of their behavior change goals, what elements in their environment they will modify in the change process, and what rewards will be used to reinforce themselves. b) This is a time for the facilitators to make sure the goals and rewards are specific and attainable. c) Group members will be urged to share their suggestions and encouragement. d) From the observations group members have made about their own and other peoples coping behaviors, facilitators will point out when abdication and attributions of responsibility occurs. Help participants recognize when they are attributing blame for their own behavior to others, and when they may be accepting someone else's responsibility. IJse of 'here and now' examples will help clarify the concept. Time: 30 to 35 minutes.

2. Large Group Activity: Guided fantasy. Instructions to the facilitators: a) Return to full group and have participants get comfortable. Darken the room and ask group members to close their eyes. b) You may use a pre-taped guided fantasy, or present your own. The following elements should be included:

1. Up to five minutes concentration on deep breathing and "letting go" of tensions with exhalations of breath.

2. Ask participants to think of a special place that is all their own where they can be comfortable and relaxed. It may be at home or away, a spot in nature, or inside a roam, or a composite of 
places they have been.

3. Guide them through each of the 5 senses, bringing detail and dimension to their mental picture. Sights, smell, tastes, sounds, and touches will be introduced.

4. They may be alone or with someone, so long as they can be themselves, free from constraint and worry. (Facilitators may suggest natural settings such as the oceanside, mountains, meadows, a private island, streams, places where it is warm and the sun shines, to initiate the guided fantasy, and then concentrate on asking the participants to bring details to their picture using the 5 senses.

5. Have the group slowly return to the present. Tell them that the place they created in their mind is one to which they can return any time they wish. Sometimes just a quick remembrance will help them to relax and cope with tense situations. Caution them that their special place is not meant to be used as an escape but rather as a means of getting in touch with their internal self, and relaxing.

c) When everyone is back to the present, turn up the lights and form a circle. d) Allow participants to share their reactions to the exercise; where they were and how they felt. This is usually a very refreshing and rejuvenating experience. Time: 45 to 50 minutes.

Homework: Instructions to students: Initiate your behavior change plan, whenever you have carried out your plan during the week, be sure to reward yourself! Write the occurrences in your journal. Also mention times when you did not follow-through with the plan. Refer to the "Behavior Change Planning Guide" and notate the specifics involved. 
These will help you find new ways to help change in the future. This behavior change plan will be ongoing throughout the remaining group sessions. You may use the process you are learning with many other behaviors you may wish to alter in your lifetime.

SESSION IV: ACCEYTING RESPONSIBILITY FOR PERSONAL BEHAVIOR CHOICES Purpose: To reinforce the concepts of personal responsibility vs. blaming or making attributions; to introduce concept of controlling your own behavior vs. giving power away; to recognize 'self-talk' as a behavior shaper.

Materials needed: Paper and pencils or pens.

Activities:

Large Group Discussion: Homework assignment. Instructions to facilitators: 1. a) Discuss the homework assignnent: "Is your behavior change plan working for you? Ask students: Are you reinforcing yourself? What kinds of responses are you getting from others? How are you feeling about it?" Time: 15 to 20 minutes.

2. Large Group Discussion: Accepting Responsibility. Instructions to facilitators: a) Using examples explain the difference between accepting responsibility for our own decisions, and attributing blame to others when we are unhappy with the consequences of our decisions. b) Make sure all members demonstrate a clear understanding of being responsible for their own behavior, making choices and decisions, experiencing consequences (both positive and non-positive), and the tendency to project or attribute blame to others. Time: 10 to 15 minutes. 3. Large Group Activity: Identifying Attributions of Responsibility. Instructions to facilitators: a) Co-facilitators enact a short drama of 
an emotion-packed adversary relationship. The particular roles chosen are up to co-facilitators for example: Two girlfriends arguing over one boyfriend, two workers arguing over a work schedule deadline, a nagging couple. b) The dialogue should provide abundant expressions of feelings from both people especially statements such as: "If it wasn't for you", and "if only you didn't", "if it wasn't for you I'd...", "You make me feel..." "It's all your fault that I...", "If they weren't all against me I'd...". c) While the drama is being enacted, group mernbers are to identify and write down as many attributions of responsibility as they can hear. d) Allow 3 to 5 minutes. e) Go around the group asking each person to share their observations. Ask: "How did it feel? Who is responsible for your feelings? Who is in control of your thoughts, feelings, and behavior?" f) Explain how we give away power when we 'let' someone else 'make' us think, feel, or behave. Bring in how drugs and alcohol also serve the same purpose: We give our personal power to control our thoughts, feelings and behavior over to the drug, and can attribute any problems which occur to the drug. Time: 40 to 50 minutes.

5. Large Group Activity: Accepting Responsibility. Instructions to facilitators: a) Have group members relax, close their eyes, and deep breath for a minute or two. b) Ask them to be aware of their 'here and now' feelings. c) Facilitators start by saying: "Now I am feeling and I am responsible for that". Each member of the group will then use the same phrase supplying their own feeling to the sentence. Go around 3 to 5 times. The facilitator may end the sequence by saying: "Now I am feeling it is time to end our session, and I am responsible for that!" Time: 10 to 15 minutes. 
Homework: Instructions to students: Practice being aware of feelings and decisions you make. Mentally rehearse, "I am responsible for the way I feel and the choices I make". In your journal outline at least two significant situations during the week. One in which you find you are attributing blame to someone else, and another one in which you felt you were receiving attributions of blame from someone else. Notate how you responded, and what you were saying to yourself mentally at the time.

SESSION V: LIFE POSITIONS AND PERSONAL CONTROL

Purpose: To reinforce concepts of personal responsibility for controlling behavior; to explore ways of coping with receiving attributions of blame. Materials needed: Stopwatch, Handout of "I'm OK, You're OK" (Appendix G), two "OK Corral" squares (Appendix H). This is a Transactional Analysis technique.

Activities:

1. Discuss progress on behavior change plan briefly. Any participant experiencing difficulty may be referred for additional individual counseling. Time: 5 minutes.

2. Large Group Discussion: Homework Assignment. Instructions to facilitators: a) Ask students: "How does it feel to take responsibility for your own thoughts, feelings, and behavior? When you notice other people attributing blame to you for their own situations, what did you do, say, think, feel?" b) Ask group members to share what they wrote in their journals. c) Ask: "What does the group member's response to the situation say about the way they are coping? How could they change 
their response? Would a different response change the behavior of the other people involved? Can we make other people change?" Time: 20 to 25 minutes.

3. Large Group Activity: Life Positions. Instructions to facilitators: a) Using "I'm OK, You're OK" handout, explain that what other people say and do toward us influences how we feel and think about ourselves. Although we cannot always change the circumstances around us, we can change how we feel about ourselves. Our life experiences do influence attitudes and positions we assume. b) Clarify any questions about the four life positions mentioned, pointing out that the positions we assume are influenced and reinforced by our own self-talk. Time: 10 minutes. 4. Small Group Activity: "OK Corral". Instructions to facilitators: a) Divide into two groups, one facilitator each. b) Using the "OK Corral" square, the facilitators will demonstrate assuming the role printed in each square. Use "Now I am feeling__ statements. c) Have each group member do the same exercise. Allow 2 to 3 minutes in each role square. d) Those group members who are not in the "corral" will act as observers and recorders of the speaker's facial and physical gestures, voice inflections and the statements made. e) Then: Allow 3 to 5 minutes for each speaker to express his/her feelings about being in each "corral", and to receive feedback from group members right after their turn. Time: 65 to 75 minutes.

Hamework: Instructions to students: Continue monitoring your thoughts, feelings and behaviors in difficult situations. Listen to your selftalk. How does it influence your thoughts, feelings, and behaviors? Who is responsible for that? 
SESSION VI: BUILDING COMMUNICATION SKILLS

Purpose: To introduce and practice the third coping skill: Communications skills; clearer understanding and better interpersonal relationships.

Materials needed: Timing device. Activities:

1. Behavior change progress reports. Time: 5 minutes.

2. Large Group Discussion: Homework assignment. Instructions to facilitators: a) Ask students: "How does your self-talk influence your thoughts, feelings, and behavior? What life positons do you find you are assuming?" Time: 10 to 15 minutes.

3. Large Group Activity: Communications Skills. Instructions to facilitators: Introduce communication skills as a way to deal with unfair attributions and to develop more productive, rewarding, and new relationships. Much misunderstanding stems from unclear communications. b) Ask for 2 volunteers or select 2 verbal group members to role play a conversation. c) One facilitator instructs one of the participants to talk about a matter of personal concern or interest without pause, regardless of the partner's response. d) Meanwhile the co-facilitator instructs the other participant to respond with irrelevant (noncomprehending or uninterested) statements. The conversation will last 2 to 3 minutes. e) As the 2 enact their 'conversation' the group observes. f) Ask the partners to tell their feelings while experiencing this. g) Also ask the group to express their observations and feelings. Time: 10 minutes.

4. Continuation of Large Group Activity: Communications Skills. 
Instructions to facilitators: Using two different group members a) instruct one to talk about a subject of personal interest or concern; and, b) instruct the other participant to respond during the conversation by changing the subject to a matter of his or her own interest or concern. Allow 2 to 3 minutes for the conversation. c) Ask participants to share what occurred and how they felt about it. Ask: "Did the conversation initiator feel listened to? Cared about?" Time: 10 minutes.

5. Small Group Activity: Paraphrase. Instructions to the facilitators: a) Describe paraphrase and demonstrate the skill of paraphrasing. b) Have the group form dyads to practice paraphrasing their partners' "feeling" statements. c) Facilitators will observe and assist the dyads. d) Return to full group. Ask how that felt: "Did you feel you were being listened to and heard?" Time: 10 to 15 minutes. 6. Snall Group Activity: Negotiating for meaning. Instructions to facilitators: a) Demonstrate the skill of negotiating for meaning. b) Have the group form different dyads and practice negotiating for meaning. One partner makes a personal statement, and the other person responds saying what he or she thinks was meant. The two discuss and negotiate until the originator of the statement can say the respondent has expressed the original meaning. Each person does this as initiator and respondent two to three times in sequence. c) Facilitators will observe and assist the dyads. Time: 15 to 20 minutes.

7. Large Group Discussion. Instructions to facilitators: a) Return to full group and discuss reactions. Ask students: "How did it feel to listen to and respond with what you thought was meant? Was it easy or hand to negotiate for meaning? Did you find you really felt 'heand'?" 
Homework: Instructions to students: Observe others, and monitor your own comnunication patterns during the week. Practice communicating with the paraphrase and negotiating for meaning methods with at least 2 different people. Write about it in your journal.

Exercises used in this session have been adapted from: Johnson, D.W. Reaching Out. Englewood Cliffs, N.J.: Prentice Hall Inc., 1972.

SESSION VII: ENHANCING POSITIVE SELF-CONCEPT

Purpose: To continue building coping and communication skills; to identify strengths; to foster positive self-concept.

Materials needed: Prepared $3 \times 5$ index cards (Appendix I), paper, pencils or pens.

Activities:

1. Behavior goals progress report. Time: 5 minutes.

2. Share homework assignment experiences. Time: 5 minutes.

3. Small Group Activity: Personal Strengths. Instructions to facilitators: a) Divide into 2 groups one facilitator per group. b) Instruct group members to make two lists, one of their past accomplishments, one of their perceived personal strengths. c) Have each person share his list with the group, the facilitator may model by going first. d) When each member has completed reading their list, the other group members each add one other observed strength to that person's list. They do this by writing on the $3 \times 5$ index cards provided, and saying: "I see you as a person who_, and I believe this because of _." e) The person receiving the feedback is instructed to remain quiet until all group members have given them their positive additional 
strength statements. f) When all have completed giving their verbal feedback, they pass their cards to that person. g) Immediately go to the next person who will read his/her own list of accomplishments and strengths. Again the group provides a round of verbal feedback, accompanied by the $3 \times 5$ index cards. h) After all group members have read their lists and received feedback the group then discusses which was easier; being the focus of positive feedback, or giving positive feedback? "Why is it hard to say and hear nice things about yourself? What happens when you like yourself?" Time: 60 to 70 minutes. 4. Continuation of small group activity: Identifying Barriers. Instructions to facilitators: a) After discussion the facilitators will model and have each group member ask the other group members to help them identify attitudes, behaviors, or environmental forces keeping them from using their strengths. b) Honest constructive feedback is essential at this point. Wherever drugs infringe upon the individuals' strengths or their use of their strengths, this should be acknowledged. c) The participants should be encouraged to paraphrase and negotiate for meaning so that the feedback is understood accurately. Time: 25 to 30 minutes.

Homework: Instructions to students: To the next group meeting bring a list of at least one and no more than 2 or 3 strengths you would like to build upon. Identify any barriers affecting/preventing/hindering your use of that strength. How might you overcome those barriers?

\section{SESSION: VIII INCREASING IDENTIFIED STREINGTHS}

Purpose: To establish goals for strength building; to identify barriers to achieving that goal; to rehearse ways of overcaning barriers 
to goals.

Materials needed: "Behavior Change Planning Guide". (Appendix F)

\section{Activities:}

1. Large Group Activity: Relaxation. Instructions to facilitators: a) Lead the group through systematic muscle relaxation using a muscle tension and release method, starting with the hands, arms, feet, legs, chest, shoulders, and ending with the head. b) Ask the participants to tighten each set of muscles mentioned, feel the tension, slowly release the tension, and focus on the heaviness and warnth of the released muscles. Time: 10 to 15 minutes.

2. Large Group Activity: Homework assignment. Instructions to facilitators: a) One at a time ask the group members to share from their homework assignment the identified strength they wish to increase, barriers they see in the way of achieving their goal, and ways they might overcome those barriers. b) Have group members then ask the group to help them identify any other possible barriers, and help them find ways to overcome all the barriers that are present. c) Facilitators will be sure that goals and means of overcoming barriers are realistic and attainable. d) The various possible goals mentioned will require that facilitators be flexible and spontaneous using role play, modeling, brainstorming, and behavioral rehearsal as they are applicable to help the group members. Time: 55 to 60 minutes.

3. Continuation of Large Group Activity: Behavior Change Plan. Instructions to facilitators: a) Using the "Behavior Change Planning Guide" have each group member write down their strength goal as a behavioral objective. b) Ask: "What will be used as encouragenent and reward? How will you know when you have achieved your goal?" Time: 10 
to 15 ininutes.

Homework: Instructions to students: Put your strength building plan into action. Monitor yourself and keep a record in your journal. Lavish praise on yourself as you accomplish even parts of your desired goal! Think about this goal in terms of your own values and your preferred lifestyle.

\section{SESSION IX: VALUES AND LIFESTYLE CHOICES}

Purpose: To relate decision making and coping skills to personal values and lifestyle choices.

Materials needed: Lined paper and construction paper, coloring and writing instruments, confortable room, activity sheet: "Life Goals" (Appendix J)

Activities:

1. Large Group Discussion: Homework assignment. Instructions to the facilitators: a) Discuss group member's progress on individual strength building plans. b) Allow time for each person to describe what sccurred during the previous week. c) Emphasize that all learning requires dedication and practice. Only when we really want the change for ourselves will we make it happen. d) Praise and reinforcement, encouragement and suggestions from facilitators and group members will help each member solidify their behavioral intent. Time: 10 to 15 minutes. 2. Large Group Activity: Guided Fantasy. Instructions to facilitators: a) Prepare room and group members for guided fantasy. b) Instruct participants to close their eyes and concentrate on their breathing. c) Lead them back to that special place they created in their minds before. Ask them to remember all the details, including 
sights, sounds, smells, tastes and touches. d) Now begin to build upon the image telling them:

1) If there is no home, build a home in your mind.

2) Put in it all the things, people and activities that you want to have in your lifetime, all that you love and that you dream about having, doing, being...

3) Keep focusing on and adding details until you have a complete picture in your mind.

4) Bring in all that you want included, and leave out that which you don't want included.

e) Then gently ask the group to return to the present. f) Give members a choice of writing about or drawing a picture of the place they created. Ask them to include as many details as they can remember. Time: 30 to 40 minutes.

4. Small Group Activity: Sharing Values and Goals. Instructions to facilitators: a) Divide into two groups with one facilitator each. b) Have participants share what they have created, giving descriptive details. c) Facilitators will use the exercise to relate how the choices made reflect both the values individual group members hold, and the lifestyle preferences they are making. Emphasize how the choices and decisions we make about our lives, affect our getting where we want to be.

5. Remind group members that the next session is the last one scheduled. Homework: Instructions to students: 1. Continue monitoring and reinforcing your 'strength behavior' goal. 2. Using "Life Goals" activity sheet, make lists of your long-term goals: a) what you want to 
accomplish in the next 5 years; b) where you expect to be in 10 years; c) what you would need to do before your life is over to be happy with yourself; and, e) what people will say about you after you're gone. Reflect on how your use of chemical substances will fit into your lifestyle. How can it keep you from your goals?

SESSION X: TERMINATING THE GROUP

Purpose: To clear up unfinished business; to express appreciation; to give and receive positive feedback, and give closure to the group. Materials needed: None.

Activities:

1. Discuss progress on strength building goals. Emphasize that the process of increasing strengths is one which is ongoing and that the same skills can be applied to other behavior change goals. Time: 10 to 15 minutes.

2. Large Group Activity: Life goals homework assignment. Instructions to facilitators: a) Instruct each group member to rank order all of the life goals they have listed. b) Then have then select the top three to reveal to the group. c) Ask: "What does the goal say about your values, and lifestyle preferences? How will chemical substance use fit into your lifestyle? How could chemical substance use or abuse keep you from achieving your goals?" Time: 55 to 60 minutes.

3. Large Group Activity: Expression of appreciation. Instructions to facilitators: a) Have group form a circle with one person in the middle. b) Instruct that person to verbally or nonverbally express their positive feelings and appreciation for each person in the circle. The co-facilitators will model first. c) Each group member should be 
encouraged to take a turn in the center of the circle. Time: 15 to 20 minutes.

4. Announce the option of having a follow-up session, and determine a time and date if the option is elected.

5. Tell everyone to express their own goodbyes for now. 
CHAPTER VI

\section{CONCLUSIONS AND RECOMMENDATIONS}

Adolescent use of chemical substances, especially marijuana and alcohol, continues to remain at alarmingly high levels. Indications are that substantial numbers of youth are using marijuana and alcohol daily, and probably are attending school classes while intoxicated.

The physical, psychological, and social effects of drug use, and especially of drug abuse, are pervasive and often lead to destructive behavior. While acute effects such as accidents, illegal behavior, mernory and time distortion, and disintegration of self-control may be immediately apparent, long term acute effects are yet to be identified. It is necessary to conduct longitudinal studies which cover early adolescence through mature adulthood in order to more accurately ascertain the physical, psychological, and social effects of early onset of chemical substance use.

Clearly environmental and personal deteminants intertwine to create conditions conducive to the initiation and maintenance of drug use. These determinants also influence the development of dependence upon chemical substance use. Whether an adolescent ever initiates drug use, and the level of maintainance of drug use are highly personalized decisions. Therefore, while it is possible to make inferences regarding those environmental and personal variables most salient to adolescent drug use/abuse, each person is influenced by a unique combination of internal and external forces. Nevertheless, research aimed at testing 
hypotheses such as that proposed by Kandel (1980), to explore predictors of sequential levels of adolescent drug usage appear to be warranted. Because the most effective prevention may be that which is antecedent to an action, drug prevention initiatives should focus attention on changing the environmental cues, stimuli, and rewards which are entrenched in our political, economical, and social policies and institutions.

Given the influence environmental systems have on the development of attitudes and behavior, much drug misuse and abuse could be averted through social change. Three specific areas which currently hold great power over social behavior and which could be used to enhance responsible drug use attitudes include: 1) appropriate legal control of drugs; 2) media and advertising portrayal of appropriate drug use, and; 3) definition of responsible chenical substance use with attached social sanctions and rituals.

The status of marijuana as an illicit drug has not prevented exploratory use by a simple majority of 16-17 year old adolescents (Peterson, 1980). The illegality of marijuana keeps its use covert, creating conditions conducive to black market operations, the development of abusive subcultures (Guydish, 1982), and supports an attitude of disdain toward social institutions. Jessor, Jessor, \& Finney (1973) summarized the effects of both legal proscription and media influences:

The mass media, in their efforts to exploit the youth culture, and even the agencies of social control themselves in their very efforts to prevent marijuana use, may well contribute to spreading a cammon definition of its social meaning to society as a whole. When the larger society is emphatic that it opposes marijuana use, it may well teach at the same time that opposition to the larger society can be expressed by using marijuana. (p. 13-14) 
Concerns about being arrested do not deter adolescents who have a positive attitude toward the act of drug use (Cook et al., 1980).

Advertising and media images which model chemical substance use for the purpose of coping with life situations, enhancing self-image, or just curing minor physical symptoms, reinforce drug and alcohol use as standard practices, and desirable behaviors. By de-emphasizing maladaptive social dependence on drugs, and removing the glamour and machismo images attached to drug use and abuse, media sources could help reshape values which adolescents place on drug use as a means of achieving both peer and self-acceptance (Eisterhold et al., 1979). Because drugs, especially alcohol and marijuana, are used by a large segment of our American population, a distinction needs to be drawn between non-destructive and self-destructive patterns of drug use (Aubrey, 1973). Certainly, we now have more clear definitions of adaptive and maladaptive alcohol use patterns than currently are available for patterns of marijuana use (Kandel, 1980). However, even though marijuana possession and use is illegal, rituals and sanctions have developed surrounding its use (Zinberg, Jacobson, \& Harding, 1975). Social forces which are known to influence alcohol using behavior could also apply to marijuana use, and when applied in socially responsible ways could influence subsequent socialization processes.

By drawing attention to the social forces which are instrumental in shaping our drinking behavior, and by focusing attention on the responsible use of alcrhol by high status models, we may be able to significantly alter the drinking behavior of young adults and other observers who are exposed to such influences. (Lied \& Marlatt, 1974, p. 54)

However, American society has adopted a restrictive-punitive approach to chemical substance experimentation, in which use of licit drugs 
(i.e. alcohol) by adults is condoned, while use of illicit drugs by adults is penalized. Use of both licit and illicit drugs by adolescents is penalized. The resulting confusion caused by this double standard appears to produce disdain for social regulation, and reinforces deceitful behavior in adolescents.

At a more private level, parents and significant other adults may provide an environmeent which would enhance responsible adolescent decisions regarding chemical substance use. Through modeling and reinforcing attitudes, values and behavior, parents can teach responsible drug using behavior (Kandel, 1980; Lied \& Marlatt, 1979). Although specific rules which parents establish against drug usage may not be effective deterrents, parental attitudes regarding drugs and parental religiosity seem to influence subseguent drug use by their offspring (Kandel, 1980). When parents self-prescribe drugs, children are likely to do the same (Gorsuch \& Butler, 1976). Because values held by parents influence values developed by their children (Bandura, 1972), less selfindulgence, higher values placed on long-range goals, and higher value placed on achievement all appear to be likely to help in preventing adolescent drug abuse (Gorsuch \& Butler, 1976; Jessor et al., 1973).

Parental use of social control over their offspring demonstrates a level of commitment to their children, and characterizes communication patterns within the family unit (Hunt, 1974; Kandel, 1980). Because laissez-faire and autocratic parenting styles are more likely to encourage adolescent drug use, parents may be well advised to use more democratic or quasi-democratic forms of social control in the family interactions (Hunt, 1974). Adolescent participation and involvement is characteristic of families with high affinity. By creating a close, 
warm, understanding and participative family environment, with fair and definitive rules, parents model democratic principles, and may reduce their offsprings' perceived need for and attraction to chemical substances and their corrollary support systems (Babst et al., 1978; Brook et al., 1980; Gorsuch \& Butler, 1976; Mercer et al., 1978).

School systems have an important role to play by providing initiatives for drug use/abuse prevention and intervention programs. Early classroom training aimed at helping children and young adolescents develop belief and attitude structures, decision-making and coping skills, and providing accurate, timely information about chemical substances, may prove to be extremely beneficial. Where long term chemical substance use/abuse programs are initiated, careful assessment procedures will help insure that the program goals and subgoals are achieved. Cross-sectional and longitudinal studies of on-going drug intervention programs will help other school districts assess potential programs and formulate their own plans for school/community coordination and involvement.

Involving other existing community services, parents, and citizens in drug abuse prevention program plans may prove economical, and supply a wealth of potential ideas and human resources. Certainly, schools need to provide treatment options to chemically dependent adolescents, as an alternative to suspension from school. Workshops or clinics offered through the schools or other public service agencies could provide parents of adolescents with infommation, and teach principles of democratic parenting, as well as conmunication skills. Within the school, those who serve as teachers, administrators, 
support service workers, and counselors all influence the atmosphere which prevails. A student population which is included in school decision-making functions will have a greater sense of personal investment in the outcomes of those decisions and the climate of the school. By fostering an attitude of caring about the total well being of the student population; by investing time, money, and energy in assisting adolescents who are experiencing drug related difficulties; and by maintaining a philosophy of accepting the individual, if not their actions, school personnel will enhance student perception of the school as a positive, helping environment.

The guidance department also has responsibility for maintaining a positive and open attitude toward drug experimenting youth. An initial step would be to acknowledge that adolescents are experimenting with drugs and establish a group counseling prograrn such as is proposed in Chapter V. Incorporating peer counselors into the guidance department plan would provide additional depth, and may contribute positively to the overall school atmosphere as well. An ongoing intervention program which includes individual, family, and group counseling at all grade levels, and which makes appropriate referrals, is integral to the success of the total school drug use/abuse prevention and intervention program. The model for group intervention proposed in Chapter $\mathrm{V}$ also may be adapted and used to enhance teacher, administrator, and parent awareness and understanding of personal attitudes and beliefs regarding chemical substance use.

Greater emphasis must be placed on providing opportunities for additional counselor training in drug abuse prevention and intervention. Adequately trained professional counseling personnel will be an asset 
as a resource for the school and the community it serves.

In conclusion, this author cautions other helping professionals not to accept automatically the 'medical model' explanation of chemical substance abuse, which proposes that substance dependence is a proyressive disease that can only be cured by total abstinance from chemical substance use. While it appears that drug dependence rehabilitation programs based on this principle (such as Alcoholics Anonymous; AA) are extremely effective in their rehabilitation efforts, salient social and psychological elements of chemical substance use and abuse are not adequately explained by the disease model. A substantial part of the success of prograns such as AA may well be the emphasis placed on renewing a spiritual life, and having a cohesive, comprehending peer. support system with abundant role models to reward and reinforce continued commitment.

These principles of self-renewal and peer group support systems should be integrated into other prevention and intervention programs. However, because not all chemical substance users or abusers necessarily are bound to become chemically dependent, the suggestion of total abstinance from chemical substance consumption must be used with care. Where chemical dependence clearly is evident, abstinance as part of the rehabilitation plan appears to be the appropriate alternative. The major task that counselors of drug experimenting youth have, however, is to help adolescents make responsible choices and decisions regarding the place chemical substance use will have in their lives. 


\section{BIBLIOGRAPHY}

Abel, E.L. Marihuana and memory: Acquisition or retrieval? Science, 173, $1971,1038-1040$.

Adler, P.T., \& Lotecka, L. Drug use among high school students; Patterns and correlates. The International Journal of the Addictions, 1973, 8, 537-548.

Akers, R.L., Krohn, M.D., Lanza-Kaduce, L., \& Radosevich, M. Social learning and deviant behavior: A specific test of a general theory. American Sociological Review, 44, 635-55, 1979.

Arnao, G. Cannabis taking as cultural deconditioning. Phoenix, Az.; The Do It Now Foundation Institute for Chemical Survival Monograph Series \#706, 1976.

Aubrey, R.F. The Counselor and Drug Abuse Programs. Boston: Houghton Mifflin Company, 1973.

Babst, D.V., Deren, S. Schmeidler, J., Lipton, D.S., \& Dembo, R. A study of family affinity and substance use. Journal of Drug Education, $1978,8,29-40$.

Bandura, A. Social Learning Theory. Englewood Cliffs, N.J.: Prentice Hall, Inc., 1977.

Bearden, w.O., Woodside, A.G., \& Jones, J.J. Beliefs and anticipated situations influencing intentions to use drugs. Perceptual and Motor Skills, 1979, 48, 743-751.

Bell, E.V. A peer mediated approach to drug education. Journal of Negro Education, 1978, 47, 3, 283-289.

Black, C. Children of alcoholics. Alcohol Health and Research World, Fall $1979,23-27$.

Braucht, G., Brakarsh, D., Follingstrad, D, \& Berry, K.L. Deviant drug use in adolescence; A review of psychosocial correlates. Psychological Bulletin, 1973, 79, 92-106.

Britt, D.W., \& Campbell, E.Q. Assessing the Linkage of norms, environments, and deviance. Social Forces, 1977, 56, 532-550.

Brook, J.S., Lukoff, I.F., \& Whiteman, M. Initiation into adolescent marijuana use. Journal of Genetic Psychology, 1980, 137, 133-142. 
Carman, R.S. Drug use and personal values of high school students. The International Journal of the Addictions, 1973, 8, 733-739.

Carney, R.E. Summary and results from 1969-1972 Values-Oriented Drug Abuse Prevention Programs. Santa Monica, Ca.: Educational Assistance Institute, 1972 .

Clark, L.D., Hughes, R., \& Nakashima, E.N. Behavioral effects of marijuana. Archives of General Psychiatry, 1970, 23, 193-198.

Columbian, The "Use of marijuana drops anong U.S. teen-agers." Wed. Feb. 24, 1982, Youth pp. 1-2, Vancouver, Wa.

Cook, M.P., Lounsbury, J.W., \& Fontenelle, G.A. An application of Fishbein and Ajzen's attitudes - subjective norms model to the study of drug use. Journal of Social Psychology, 1980, 110, 2, 93-201.

Eisenman, R., Grossman, J.C., \& Goldstein, R. Undergraduate marijuana use as related to internal sensation novelty seeking \& openness to experience. Journal of Clinical Psychology, 1980, 36, 4, 1013-1019.

Eisterhold, M.J., Murphy, P., Beneke, W., \& Scott, G. Multiple drug use among high school students. Psychological Reports, 1979, 44, 10991106.

Fishbein, M., \& Ajzen, I. Belief, Attitude, Intention, and Behavior: An Introduction to Theory and Research. Reading, Mass.: Addison-Wesley, T975.

Frankel, P., Behling, C.F., \& Dix, T. The parents of drug users. Journal of College Student Personnel, 1975, 16, 3, 244-247.

Gantman, C.A. Family interaction patterns among families with nomal, disturbed, and drug-abusing adolescents. Journal of Youth and Adolescence, $1978,7,4,429-440$.

Goodman, J.K. Preventing the causes of drug abuse. Journal of Druq Education, 1972, 2, 263-268.

Goodwin, D.W., Schulsinger, F., Hermansen, L., Guze, S.B., \& Winokur, G. Alcohol problems in adoptees reared apart from alcoholic biological parents. Archives of General Psychiatry, 1973, 28, 238-243.

Gorsuch, R.L., \& Butler, M.C. Initial drug abuse: A review of predisposing social and psychological factors. Psychological Bulletin, $1976,83,120-137$.

Gould, K.C., Berberian, R.M., Kasl, S., Thompson, W.D., \& Kleber, H.D. Seguential patterns of multiple drug use among high school students. Archives of General Psychiatry, 1977, 34, 216-222. 
Graham, D.L., \& Cross, W.C. Values and attitudes of high school drug users. Journal of Drug Education, 1975, 5, 2, 97-107.

Green, M.G., Blake, B.F., Carboy, G.J., \& Zenhausen, R.T. Proceedings of the Annual Convention of the American Psychological Association. 1971, 6 (pt. 2), 559-560.

Grinspoon, L. \& Bakalar, J.B. Marihuana: Health hazards and medical ben efits. In: J.P. Brady \& H.K. Brady (Fds.), Controversy in Psychiatry. Philadelphia: W.B. Saunders, 1978, 881-904.

Guydish, J. Substance abuse and alphabet soup. The Personnel and Guidance Journal, $1982,60,7,397-401$.

Henbree, W.C., Nahas, G.G., \& Huang, H.F.S. Changes in human spermatozoa associated with high dose marihuana smoking. In: G.G.Nahas, and W.D.M. Paton (Eds.), Marihuana: Biological Effects. New York: Pergamon Press, 1979, $\overline{429-439}$.

Hogan, R., Mankin, D., Conway, J., \& Fox, S. Personality correlates of undergraduate marijuana use. Journal of Consulting \& Clinical Psychology, 1970, 35, 58-63.

Horan, J.J. Outcome difficulties in drug education. Review of Educational Research, 1974, 44, 203-211.

Huba, G.J., Wingard, J.A., \& Bentler, P.M. Longitudinal analysis of the role of peer support, adult models, \& peer subcultures in beginning adolescent substance use: An application of setwise canonical correlation methods. Multivariate Behavioral Research, 1980, 15, 3, 259-279.

Hunt, D.G. Parental permissiveness as perceived by the offspring and the degree of marijuana usage among offspring. Human Relations, 1974, 27, $267-285$.

James, M., \& Jongeward, D. Born To Win. Chicago, Ill.: Signet, 1978.

Jessor, R., Carman, R., \& Grossman, P. Expectations of need satisfaction and drinking patterns of college students. Quarterly Journal of Studies on Alcohol, 1958, 29, 101-116.

Jessor, R., Collins, M.I., \& Jessor, S.L. On becoming a drinker: Socialpsychological aspects of an adolescent transition. Annals of the New York Academy of Sciences, 1972, 197, 199-213.

Jessor, R., Jessor, S.L., \& Finney, J. A social psychology of marijuana use: Longitudinal studies of high school and college youth. Journal of Personality and Social Psychology, 1973, 26, 1, 1-15.

Johnson, D.W. Reaching Out. Englewood Cliffs, N.J.: Prentice Hall Inc., 1972 . 
Johnson, B.D. Marijuana Users and Drug Subcultures. New York: Wiley, 1973.

Johnston, L. Drug Use Among American High School Students, 1975-1977. Rockville, Md.: National Institute on Drug Abuse, 1977.

Johnston L.D., Bachman, J.G., \& O'Malley, P.M. Drugs and the Class of '78: Behaviors, Attitudes, and Recent National Trends. Rockville, Md.: National Institute on Drug Abuse, 1979. (a)

Johnston, L.D., Bachinan, J.G., \& O'Malley, P. 1979 Highlights: Drugs and the Nations High School Students - Five Year National Trends. Rockville, Md.: National Institute on Drug Abuse, 1979. (b)

Jones, M.C. Correlates and antecedents of adult drinking patterns. Paper presented at the meeting of the Western Psychological Association, Honolulu, June 1965.

Jones, M.C. Personality correlates and antecedents of drinking patterns in adult males. Journal of Consulting and Clinical Psychology, $1968,32,2-12$.

Jones, M.C. Personality antecedents and correlates of drinking patterns in women. Journal of Consulting and Clinical Psychology, 1971, 36, $61-69$.

Jones, R.'T. \& Benowitz, N. The 30-day trip - Clinical studies of cannabis tolerance and dependence. In: M.C. Braude and S. Szara (Eds.), Pharmacology of Marihuana. New York: Raven Press, 1976, 627-642.

Jones, R. Human ef fects. In: R.C. Petersen, (Ed.), NIDA Research Monograph 14, Marihuana Research Findings: 1976, Washíngton, D.C.: U.S. Goverment Printing office, 1977, 128-178.

Kaij, L. Alcoholism in Twins; Studies on the Etiology and Sequels of Abuse of Alcohol. Stockholm: Almgvist and Wiksell, 1960.

Kandel, D.B., Kessler, R.C., \& Margulies, R.z. Antecedents of adolescent initiation into stages of drug use: A developmental analysis. Journal of Youth and Adolescence, 1978, 7, 13-40.

Kandel, D.B. Drug and drinking behavior among youth. Annual Review of Sociology, $1980,6,235-285$.

Kaplan, H.B. Antecedents of deviant responses: Predicting from a general theory of deviant behavior. Journal of Youth and Adolescence, 1977, $7,253-277$.

Klonoff, H. Effects of marijuana on driving in a restricted area and on city streets: Driving performance and physiological changes. In: L.L. Miller (Ed.), Mari juana: Effects on Human Behavior. New York: Academic Press, 1974, 359-397. 
Kolansky, H., \& Hoore, W. Effects of marijuana on adolescents and young adults. Journal of the American Medical Association, 1971, 216, 486-493.

LaDriere, M.L., Odell, R.E. Jr., \& Pesys, E. Marijuana: It's meaning to a high school population. The Journal of Psychology, 1975, 91, 297307.

Lawrence, T.S., \& Velleman, J.D. Correlates of student drug use in a suburban high school. Psychiatry, 1974, 37, 129-136.

Lied, E.R., \& Marlatt, G.A. Modeling as a determinant of alcohol consumption: Effect of subject sex and prior drinking history. Addictive Behaviors, 1979, 4, 1, 47-54.

Lucas, W.L., Grupp, S.E., \& Schmitt, R.L. Predicting who will turn on: A four year follow-up. The International Journal of the Addictions, $1975,10,2,305-326$.

Lucas, W.L. Predicting initial use of marijuana from correlates of marijuana use: Assessment of panel and cross-sectional data 1969-1976. The International Journal of the Addictions, 1978, 13, 7, 1035-1047.

McAree, C., Steffenhagen, R., \& Zheutlin, L. Personality factors in college drug users. International Journal of Social Psychiatry, 1969, $15,102-106$.

McClelland, D.C. The power of positive drinking. Psychology Today, 1971, $4,40-41,78-79$.

Melges, F.T., Tinklenberg, J.R., Hollister, L.E., \& Gillespie, H.K. Marihuana and the temporal span of awareness. Archives of General Psychiatry, 1971, 24, 564-567.

Mercer, G., Hundleby, J., \& Carpenter, R. Adolescent drug use and attitudes toward the family. Canadian Journal of Behavioral Science, $1978,10,79-90$.

Miller, L.L., Drew, W.G., \& Kiplinger, G.F. Effect of marijuana on recall of narrative material and Stroop color-Word performance. Nature, 1972, 237, 172-173.

Miller, L.L., \& Drew, W.G. Cannabis: Neural mechanisms and behavior. In: L.L. Miller (Ed.), Marijuana: Effects on Human Behavior. New York: Academic Press, 1974, 158-182.

Miller, M. G. Domestic Violence In Oregon. Salem, Or.: Governor's Commission for Women, Sept. 1979.

National Institute on Alcohol Abuse and Alcoholism. Second Report to the U.S. Congress on Alcohol and Health. Rockville, Md.: U.S Government Printing Office, 1974. 
National Institute on Alcohol Abuse and Alcoholism. Third Special Report to the U.S. Congress on Alcohol and Health. Washington D.C.: U.S. Government Printing Office, 1978.

Nowlan, R., \& Cohen, S. Tolerance to marihuana: Heartrate and subjective "high". Clinical Pharmacology and Therapy, 1977, 22, 550-556.

Omenn, G.S., \& Motulsky, A.G. A biochemical and genetic approach to alcoholism. In: F.E. Seixas (Ed.), Nature and Nurture in Alcoholism. New York: Annals of the New York Academy of Sciences, 1972.

O'Neil, J.M. Patterns of gender role conflict and strain: Sexism and fear of femininity in men's lives. The Personnel and Guidance Journal, 1981, 60, 4, 203-210.

Parker, F. Self-role strain and drinking disposition at a prealcoholic age level. Journal of Social Psychology, 1969, 78, 55-61.

Partanen, J., Bruun, K., \& Markkanen, T. Inheritance of Drinking Behavior; a Study of Intelligence, Personality, and Use of Alcohol in Adult Twins. Helsinki: Finnish Foundation for Alcohol Studies, Piblication No. $14,1966$.

Pearlman, S. Drug use and experience in an urban college population. American Journal of Orthopsychiatry, 1968, 38, 503-514.

Peterson, R. C. Marijuana and Health: Eighth Annual Report to the U.S. Congress From the Secretary of Health and Human Services 1980. Rockville, Md.: National Institute on Drug Abuse, 1980.

Ray, O.S. Drugs, Society, and Human Behavior. St. Louis: C.U. Mosby Company, 1972.

Rosenberg, C.M. Determinants of psychiatric illness among young people. British Journal of Psychology, 1969, 115, 907-915.

Rosenkrantz, H., \& Fleischman, R.W. Effects of cannabis on lungs. In: G.G. Nahas \& W.D.M. Paton, (Eds.), Marihuana: Bioloqical Effects. New York: Pergamon Press, 1979, 279-300.

Rossi, A.M., \& O'Brien, J. Memory and time estimation. In: J.H. Mendelson, A.M. Rossi, \& R.E. Meyer (Eds.), The Use of Marijuana: A Psychological and Physiological Inquiry. New York: Plenum Press, 1974, 89-106.

Roucek, J., \& Roland, W.L. Sociology: An Introduction. Ottowa, Canada: Littlefield, Adams \& Co., 1965.

Sadava, S.W. Initiation to cannabis use: A longitudinal social psychological study of college freshmen. Canadian Journal of Behavioral Science, 1973, 5, 371-384. (a) 
Sadava, S.W. Patterns of college student drug use: A longitudinal social learning study. Psychological Reports, 1973, 33, 75-86. (b)

Sadava, S., \& Forsyth, R. Drug use and a social psychology of change. British Journal of Addictions, 1976, 71, 333-342.

Sadava, S., \& Forsyth, R. Person-environment interaction and college student drug use: A multivariate longitudinal study. Genetic Psychology Monographs, 1977, 96, 211-245.

Sassenrath, E.N., Chapman, L.F., \& Goo, G.P. Reproduction in Rhesus monkeys chronically exposed to delta-9-THC. In: G.G. Nahas, \& W.D.M. Paton, (Eds.), Marihuana: Biological Effects. New York: Pergamon Press, 1979, 501-512.

Scherer, S.E. Fttinger, R.F., \& Mudrich, N.J. Need for social approval and drug use. Journal of Consulting and Clinical Psychology, 1972, $38,1,118-121$.

Schlegel, R.P., \& Norris, J.E. Effects of attitude change on behaviors for highly involving issues: The case of marijuana smoking. Addictive Behaviors, 1980, 5, 2, 113-124.

Seixas, F.E. Nature and Nurture in Alcoholism. New York: Annals of the New York Academy of Sciences, 1972.

Single, E., Kandel, D.B., \& Faust, R. Patterns of multiple drug use in high school. Journal of Health and Social Behavior, 1974, 15, 344357.

Smart, R.G., \& Fejer, D. Illicit drug users: Their social backgrounds, drug use and psychopathology. Journal of Health and Social Behavior, $1969,10,297-308$.

Steffenhagen, R., McAree, C., \& Zheutlin, L. Social and academic factors associated with drug use on the University of Vermont campus. International Joural of Social Psychiatry, 1969, 15, 92-96.

Stuart, R.B. Teaching facts about drugs: pushing or preventing? Journal of Educational Psychology, 1974, 66, 189-200.

Tinklenberg, J.R., Kopell, B.S., Melges, F.T., \& Hollister, L.E. Marijuana and alcohol: time production and memory functions. Archives of General Psychiatry, 1972, 27, 812-815.

Tudor, C.G., Petersen, D.M., \& Elifson, K.W. An examination of the relationship between peer and parental influences and adolescent drug use. Adolescence, $1980,15,60,783-798$.

Victor, H.R., Grossman, J.C., \& Eisenman, R. Openness to experience and marijuana use in high school students. Journal of Consulting and Clinical Psychology, 1973, 41, 1, 78-85. 
Vogt, A.T. Will classroom instruction change attitudes toward drug abuse? Psychological Reports, 1977, 41, 973-974.

Wegscheider, S. The Family Trap. Crystal, Minn.: Nurturing Networks, 1979 .

Williams, A. Social drinking, anxiety and depression. Journal of Personality and Social Psychology, 1966, 3, 689-693.

Wingard, J.A., Huba, G.J., \& Bentler, P.M. The relationship of personality structure to patterns of adolescent marijuana substance use. Multivariate Behavioral Research, 1979, 14, 2, 131-143.

Worden, M., \& Rosellini, G. Problem Drinking Continuum: A Tool for Treatment, Training and Education. Phoenix, Az.: Do It Now PublicaEions, 1981.

Wright, J. Students can be effective change agents. National Association of Secondary School Principals Bulletin, 1979, 63, 424, 44-49.

Yancy, W.S., Nader, P.R., \& Burnham, K. Drug use and attitudes of high school students. Pediatrics, 1972, 50, 5, 739-745.

Zinberg, N.E., Jacobson, R.C., \& Harding, W.M. Social sanctions and rituals as a basis for drug abuse prevention. American Journal of Drug and Alcohol Abuse, 1975, 2, 165-182. 
APPENDIX A

FEFDBACK

"Feedback" is a way of helping another person to consider changing their behavior. It is communication to a person (or group) which gives them information about how they affect others. As in a guided missile system, feedback helps an individual keep their behavior on target and, thus, better achieve their goals.

Some criteria for useful feedback:

1. It is descriptive rather than evaluative. By describing one's own reaction, it leaves the individual free to use it or to use it as one sees fit. By avoiding evaluation language, it reduces the need for the individual to react defensively. (Non Judgemental)

2. It is specific rather than general. To be told that one is "dorninating" may not be as useful as to be told that "just now when we were deciding the issue you did not listen to what others said and I felt forced to accept your arquments or be attacked by you."

3. It takes into account the needs of both the receiver and giver of feedback. Feedback can be destructive when it serves only our own needs and fails to consider the needs of the person on the receiving end.

4. It is directed towards behavior which the receiver can do something about. Frustration is only increased when a person is reminded of some shortcoming which is resistant to change. (Avoid Antagonism)

5. It is solicited, rather than imposed. Feedback is most useful when the receiver has formulated the kind of question which those observing can help to answer.

6. It is well-timed. In general, feedback is most useful at the earliest opportunity after the given behavior, depending, of course, on the person's readiness to hear it, support available from others, etc.

7. It is checked to insure clear communication. One way of doing this is to have the receiver try to rephase the feedback he/she has received to see if it corresponds to what the sender had in mind. (Paraphrase)

8. When feedback is given in a training group, both giver and receiver have the opportunity to check with others in the qroup the accuracy of the feedback. Is this one person's impression or an impression shared by others? 
APPENDIX B

*DEFINITION OF SELF-DISCLOSURE

Self-disclosure means expressing your reaction to what is happening right now, and bringing in any relevant information from your past experiences which helps someone else understand your reaction. Usually self-disclosure means you express your feelings about what is going on between you and your environment in the present. Self-disclosure, when used appropriately, helps other people understand your feelings and your reactions. Being honest and sincere about your feelings will help you build stronger, more trusting and meaningful friendships. Being self-disclosing carries with it the responsibility of listening to others and hearing their self-disclosures as well.

*Adapted from Johnson, D.W. Reaching Out. Englewnod Cliffs, N.J.: Prentice Hall Inc., 1972. 


$$
\|
$$




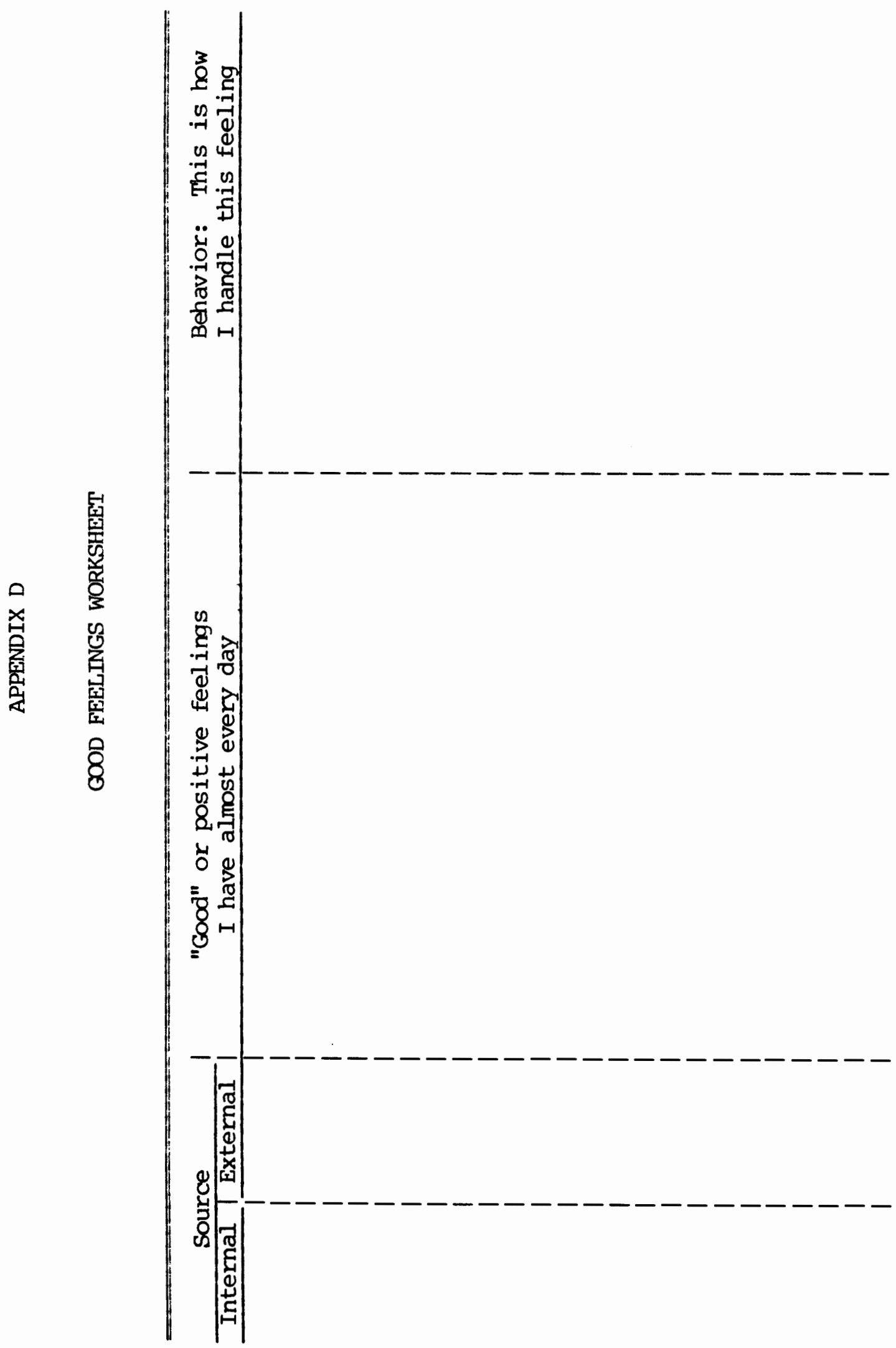




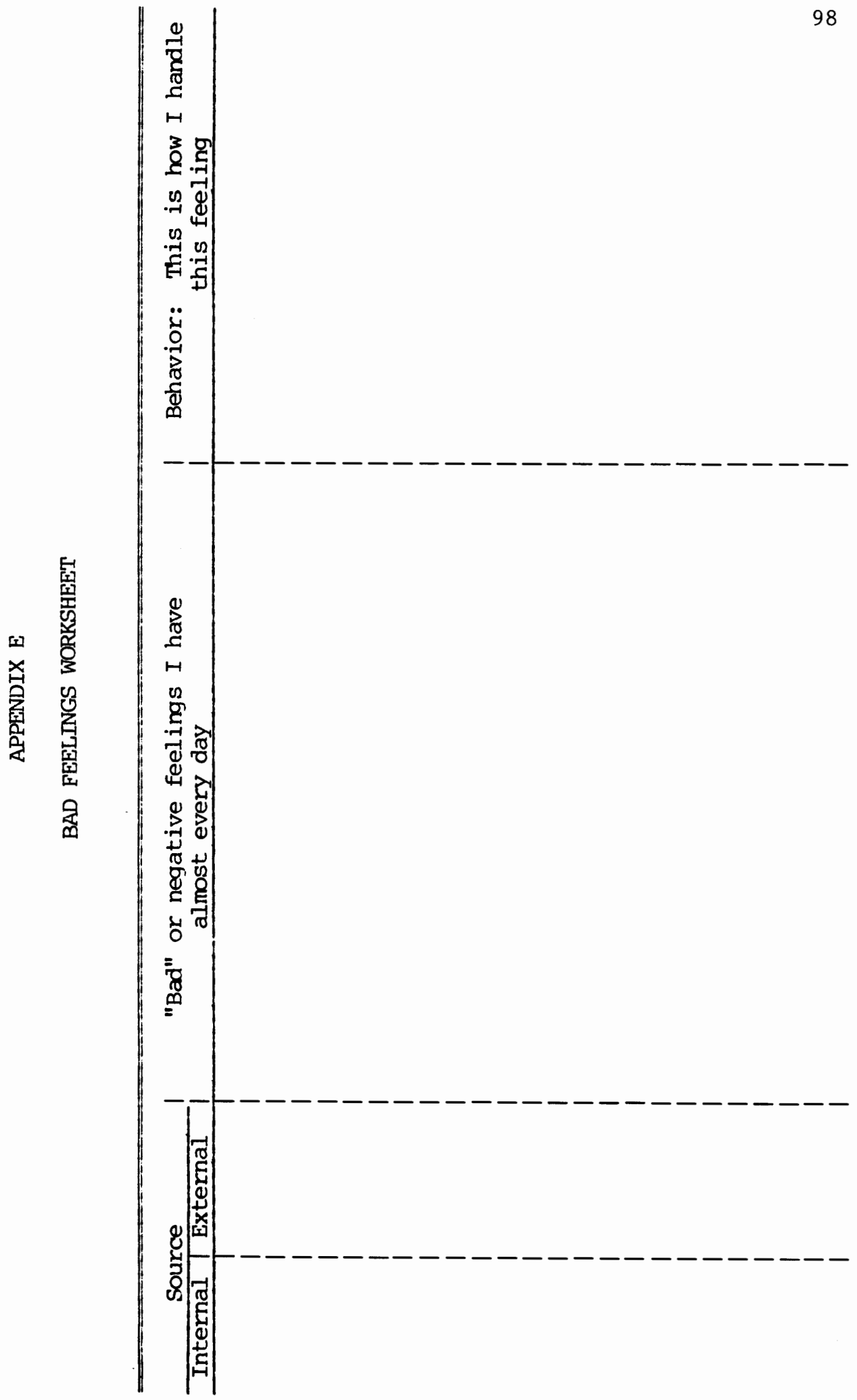


APPENDIX F

BEHAVIOR CHANGE PLANNING GUIDE

1. State your goal. What are you going to change in yourself, and in what situation will this change be occuring?

My goal is

2. If your goal is complex, what are some smaller subgoals that are steps toward achieving the whole goal?

3. What specific behaviors will be involved in attaining each subgoal?

4. What barriers to achieving your goal(s) have you identified? (thoughts, feelings, other people, situations, opportunities)

5. What could you change antecedently to help you achieve your goals?

6. Who could you observe or spend time with and learn from them by 'imitating' them?

7. What specifically will you use to reward and reinforce yourself for achieving your goal(s)? (self-praise, things or activities you like)

8. How will you know you have accomplished your goal? 


\section{APPENDIX G}

\section{*LIFE POSITIONS}

1. "I'm OK, You're OK" - When people look at the world from this point of view they feel good about themselves and about other people. They generally are able to cope with situations positively, and accept responsibility for their own behavior.

2. "I'M OK, You're not-OK" - People who operate from this point of view are pretty distrustful of other people. Usually they believe that others are to blame for what happens to them. One way they cope with adversity is to shift responsibility from themselves to others.

3. "I'm not-OK, You're OK" - People who feel this way generally are depressed most of the time. Often they do not think they compare favorably with other people or to their own self-expectations. They see themselves as having little control over their situation and commonly cope with adversity by withdrawing.

4. "I'm not-OK, You're not-OK" - Life is a 'no win' situation fram this person's point of view. People who feel this way lose any interest in living because it doesn't seem worth the effort. In extreme cases, they may commit suicide or kill other people. They blame themselves and the world for the situation they are in, and see no way of getting out of it. They feel helpless and hopeless most of the time.

*Adapted fram James, M. \& Jongeward, D. Born To Win. Chicago, Ill.: Signet, 1978. 
APPENDIX H

"OK CORRAL"

Materials needed: Large plain paper like butcherpaper, enough to make two $3^{\prime} \times 3^{\prime}$ or $4^{\prime} \times 4^{\prime}$ squares. Wide tip felt marking pen.

Procedure: On each square make a cross dividing it into four equal squares. In each corner write one of the 4 life positions as indicated in the example.

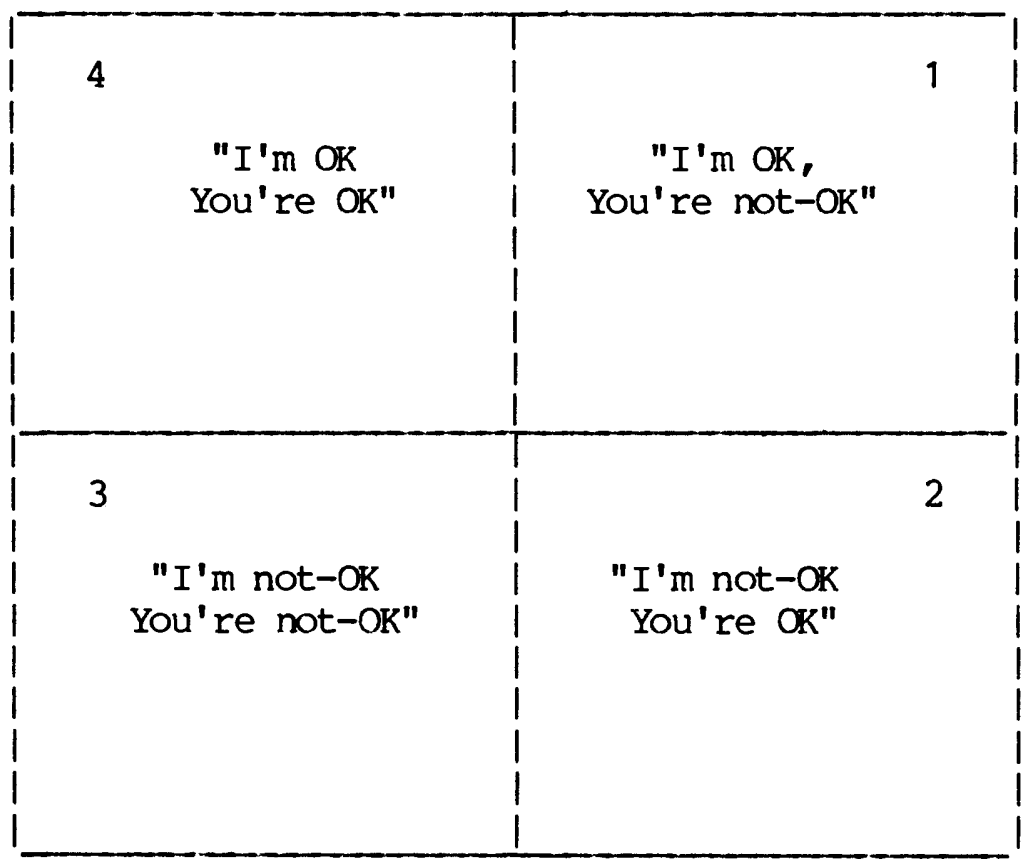




\section{APPENDIX I}

INDEX CARD FORMAT

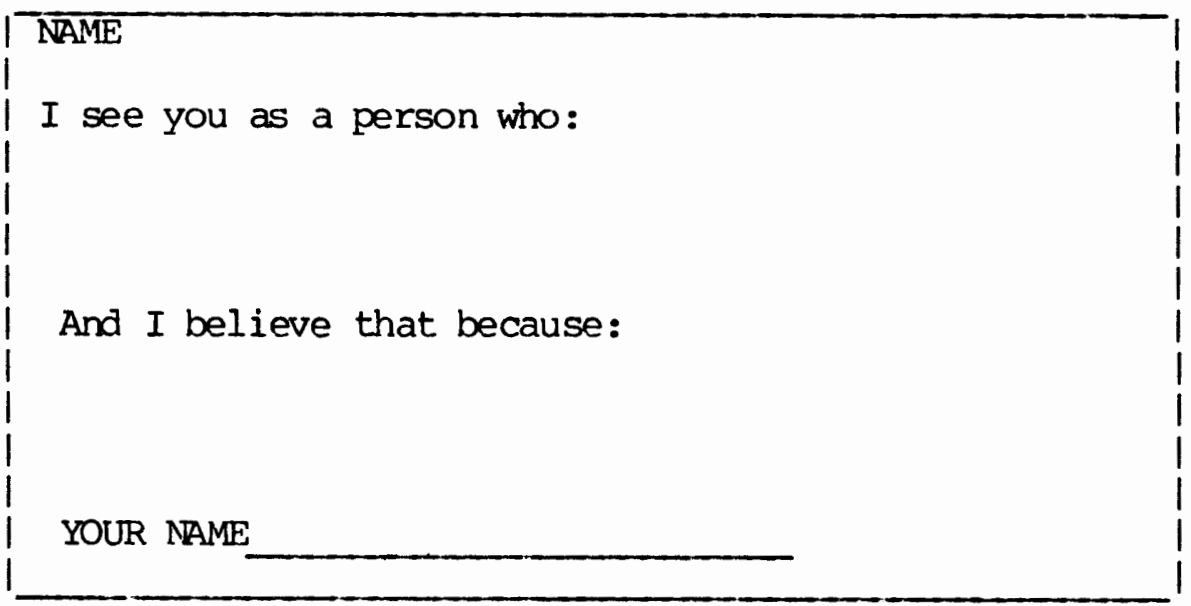




\section{APPENDIX J}

LIFE GOALS WORKSHEET

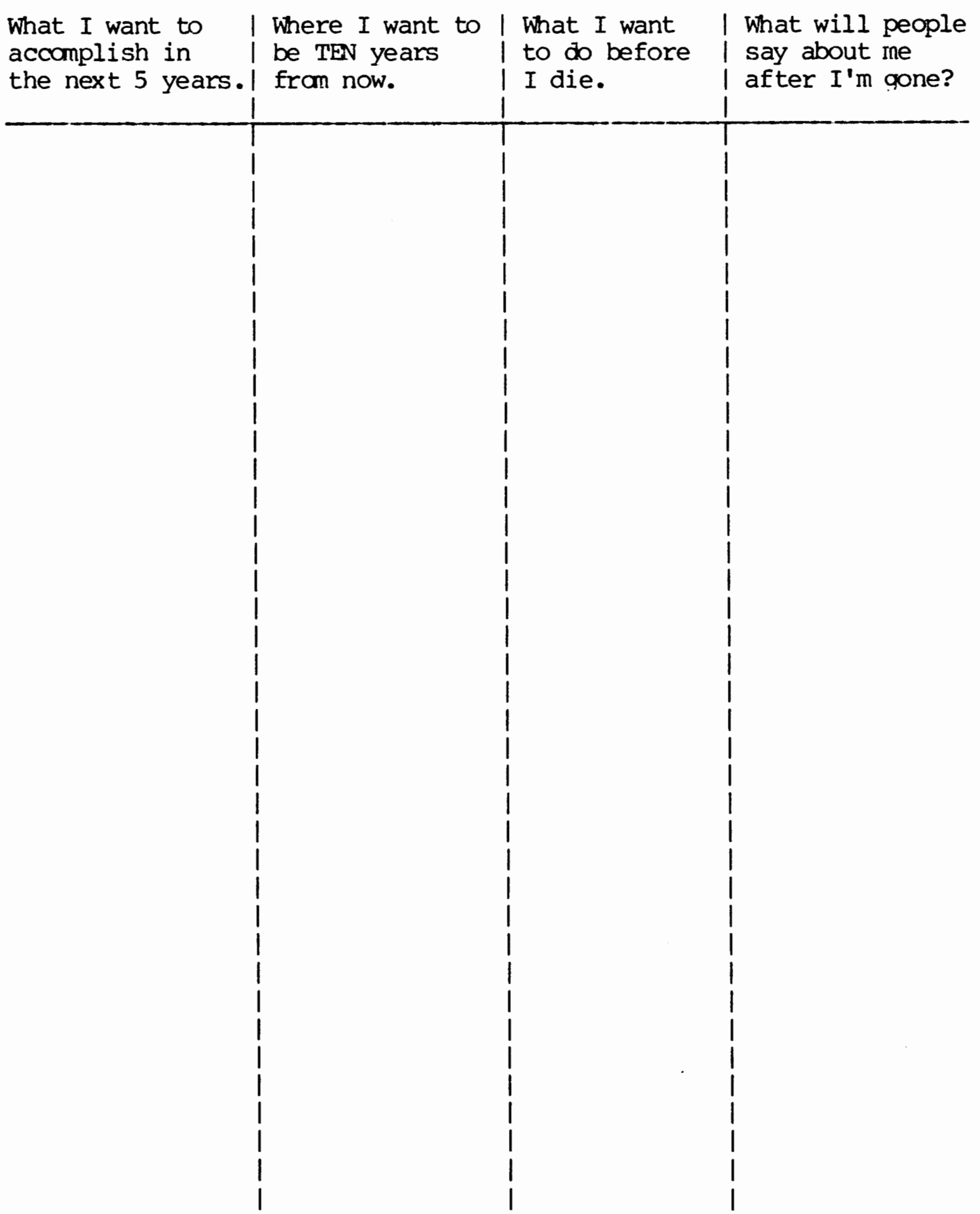

